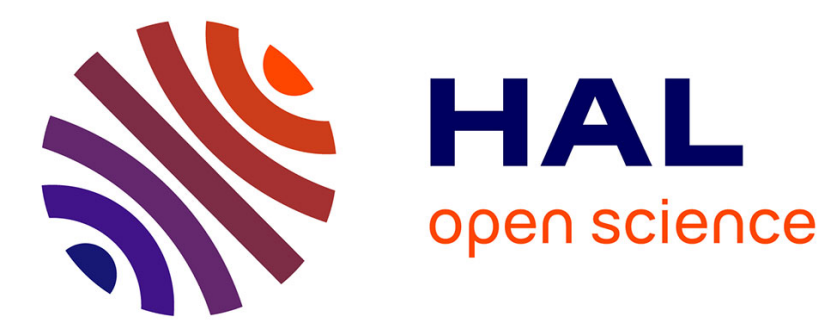

\title{
Enzymatic Formation of an Artificial Base Pair Using a Modified Purine Nucleoside Triphosphate
}

Marie Flamme, Pascal Röthlisberger, Fabienne Levi-Acobas, Mohit Chawla, Romina Oliva, Luigi Cavallo, Gilles Gasser, Philippe Marlière, Piet Herdewijn, Marcel Hollenstein

\section{To cite this version:}

Marie Flamme, Pascal Röthlisberger, Fabienne Levi-Acobas, Mohit Chawla, Romina Oliva, et al.. Enzymatic Formation of an Artificial Base Pair Using a Modified Purine Nucleoside Triphosphate. Journal of the American Chemical Society, 2020, 15 (11), pp.2872-2884. 10.1021/acschembio.0c00396 . hal-02975957

\section{HAL Id: hal-02975957 \\ https://hal.science/hal-02975957}

Submitted on 23 Oct 2020

HAL is a multi-disciplinary open access archive for the deposit and dissemination of scientific research documents, whether they are published or not. The documents may come from teaching and research institutions in France or abroad, or from public or private research centers.
L'archive ouverte pluridisciplinaire HAL, est destinée au dépôt et à la diffusion de documents scientifiques de niveau recherche, publiés ou non, émanant des établissements d'enseignement et de recherche français ou étrangers, des laboratoires publics ou privés. 


\section{ENZYMATIC FORMATION OF AN ARTIFICIAL BASE PAIR USING A MODIFIED PURINE NUCLEOSIDE TRIPHOSPHATE}

Marie Flamme ${ }^{1,2,5}$, Pascal Röthlisberger ${ }^{1}$, Fabienne Levi-Acobas ${ }^{1}$, Mohit Chawla ${ }^{3}$, Romina Oliva ${ }^{4}$, Luigi Cavallo $^{3}$, Gilles Gasser ${ }^{5}$, Philippe Marlière ${ }^{6}$, Piet Herdewijn ${ }^{7}$ and Marcel Hollenstein ${ }^{1 *}$

${ }^{1}$ Institut Pasteur, Department of Structural Biology and Chemistry, Laboratory for Bioorganic Chemistry of Nucleic Acids, CNRS UMR3523, 28, rue du Docteur Roux, 75724 Paris Cedex 15, France

${ }^{2}$ Université Paris Descartes, Sorbonne Paris Cité, 12 rue de l'École de Médecine, 75006 Paris, France.

${ }^{3}$ King Abdullah University of Science and Technology (KAUST), Physical Sciences and Engineering Division, Kaust Catalysis Center, Thuwal, 23955-6900 Saudi Arabia

${ }^{4}$ Department of Sciences and Technologies, University Parthenope of Naples, Centro Direzionale Isola C4, 80143, Naples, Italy

${ }^{5}$ Chimie ParisTech, PSL University, CNRS, Institute of Chemistry for Life and Health Sciences, Laboratory for Inorganic Chemical Biology, 75005 Paris, France.

${ }^{6}$ University of Paris Saclay, CNRS, iSSB, UEVE, Genopole, 5 Rue Henri Desbrueres, 91030 Evry, France

${ }^{7}$ KU Leuven, Rega Institute for Medical Research, Medicinal Chemistry, Herestraat, 3000 Leuven, Belgium *marcel.hollenstein@pasteur.fr 


\begin{abstract}
The expansion of the genetic alphabet with additional, unnatural base pairs (UBPs) is an important and long standing goal in synthetic biology. Nucleotides acting as ligands for the coordination of metal cations have advanced as promising candidates for such an expansion of the genetic alphabet. However, the inclusion of artificial metal base pairs in nucleic acids mainly relies on solid-phase synthesis approaches and very little is known on polymerase-mediated synthesis. Herein, we report the selective and high yielding enzymatic construction of a silver-mediated base pair $\left(\mathbf{d I m}^{\mathrm{C}}-\mathrm{Ag}^{\mathrm{I}}-\mathbf{d P u r} \mathbf{r}^{\mathrm{P}}\right)$ as well as a two-step protocol for the synthesis of DNA duplexes containing such an artificial metal base pair. Guided by DFT calculations, we also shed light into the mechanism of formation of this artificial base pair as well as into the structural and energetic preferences. The enzymatic synthesis of the $\mathbf{d I m}^{\mathbf{C}}-\mathrm{Ag}^{\mathrm{I}}-\mathbf{d P} \mathbf{\text { ur }}{ }^{\mathrm{P}}$ artificial metal base pair provides valuable insights for the design of future, more potent systems aiming at expanding the genetic alphabet.
\end{abstract}




\section{INTRODUCTION}

The expansion of the genetic alphabet with additional, artificial base pairs is a long standing goal in synthetic biology. ${ }^{1-2}$ The design of these artificial base pairs mainly relies on complementary hydrogen bonding, ${ }^{3-4}$ hydrophobic interactions ${ }^{5}$ or geometric complementarity. ${ }^{6-7}$ Expanded genetic systems have served as foundation of semi synthetic organisms able to store and retrieve increased information in their DNA which in turn could potentially permit the creation of proteins with new properties and structures..$^{8-10}$ This increased chemical diversity has also been used to develop modified aptamers with improved affinity and selectivity. ${ }^{11-15}$ Metal ion coordination has lately emerged as an alternative strategy for the creation of UBPs. ${ }^{16-28}$ Such artificial metal base pairs are indeed orthogonal to the natural Watson-Crick base pairs, are water soluble, possess a high thermal stability and do not cause any perturbation to the structure of canonical duplexes. ${ }^{29-30}$ Moreover, unlike some of the cyclic $\pi$-conjugated analogues which can be photoactivated by near-visible light, metal base pairs do not necessarily absorb ultraviolet light and thus do not produce any reactive oxygen species which are highly toxic for DNA and cells. ${ }^{31-32}$ The presence of a metal also offers the possibility of constructing novel devices such as metal nanowires or DNA-based logic gates. ${ }^{33-35}$ Yet, most metal base pairs are incorporated into synthetic oligonucleotides and surprisingly, very little is known about their enzymatic formation. ${ }^{18-19,36-38}$

In this context, we have recently investigated the enzymatic construction of two imidazole containing nucleotides (1 and $\mathbf{2}$ in Fig. 1).

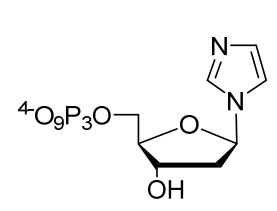

1

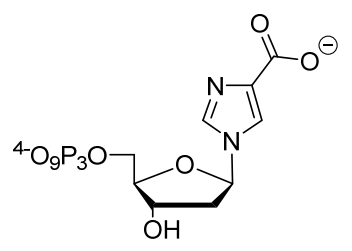

2

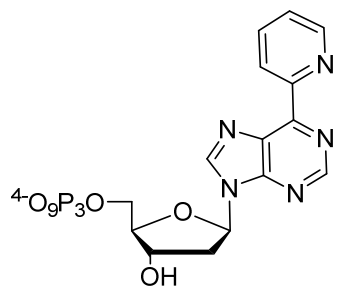

3

Figure 1. Chemical structures of the modified $\operatorname{dImTP} 1, \mathbf{d I m}^{\mathrm{C}}$ TP 2 and $\mathbf{d P u r}{ }^{\mathrm{P}}$ TP 3 nucleotides.

The biochemical analysis carried out with nucleotide $\mathbf{d} \operatorname{ImTP} 1$ revealed that, in addition to the requirements of a strong thermal stability of the metal UBP and a low structural perturbation, multiple parameters affect the enzymatic construction of artificial metal base pairs. Additional effects that need to be taken into consideration for the design of novel candidates include size-complementarity, $\pi$-stacking, hydrophobic and minor groove interactions. ${ }^{39}$ In view of these findings, we designed nucleotide $\mathbf{d I m}{ }^{\mathbf{C}} \mathbf{T P} \mathbf{2}$, which has an 
additional carboxy group on position 4 of the imidazole moiety. This was meant to increase the coordination environment and to reduce hydrogen-bonding to the canonical nucleotides. ${ }^{26}$ This second imidazole generation nucleotide was shown to be able to form an artificial metal base pair with $\mathrm{Ag}^{\mathrm{I}}$ in $\mathrm{a}[2+1]$ coordination environment under enzymatic synthesis conditions. However, no multiple incorporations could be observed and the efficiency of the formation of $\mathbf{2}-\mathrm{M}^{\mathrm{n}+}-\mathbf{2}$ base pairs remained modest, which prevents the use of $\mathbf{2}$ for the construction of libraries to be used in selection experiments. ${ }^{40}$ Here, we evaluate the effect on the efficiency of the enzymatic construction of artificial metal base pairs of increased stacking and minor groove interactions. To do so, we focused on the 6-pyridylpurine nucleoside $\operatorname{dPur}^{\mathbf{P}}$ ( 3 in Fig. 1), which has been shown to form extremely stable metal base pairs with $\mathrm{Ni}^{\mathrm{II}}$ cations ${ }^{41}$ and which presents a larger aromatic ring system and sustains interactions with polymerases through the minor groove acceptor nitrogen at $N 3{ }^{42}$

Herein, we demonstrate the efficient enzymatic synthesis of a $\mathbf{d I m}^{\mathrm{C}}-\mathrm{Ag}^{\mathrm{I}}-\mathbf{d P u r}{ }^{\mathbf{P}}$ artificial metal base pair. We also have developed a two-enzyme strategy that permits bypassing of the artificial metal base pair and allows enzymatic synthesis of DNA containing this metal UBP. Surprisingly, the expected formation of a $\mathbf{d P u r}^{\mathrm{P}}-\mathrm{Ni}^{\mathrm{II}}-\mathbf{d P} \mathbf{u r}^{\mathbf{P}}$ base pair was not observed and only a $\mathbf{d P u r} \mathbf{r}^{\mathrm{P}}-\mathrm{Ag}^{\mathrm{I}}-\mathbf{d P u r} \mathbf{r}^{\mathbf{P}}$ base pair could be constructed albeit in moderate yields. Quantum mechanics calculations showed that such metal base pairs could form and gave an insight into their mechanism of formation in the context of enzymatic synthesis.

\section{RESULTS AND DISCUSSION}

\section{Synthesis of the modified triphosphate and modified oligonucleotides}

In order to evaluate the possibility of using the 6-pyridylpurine nucleoside $\mathbf{d P u r}^{\mathbf{P}}$ to form artificial metal base pairs using polymerases we needed to synthesize the corresponding triphosphate and phosphoramidite building blocks. To do so, we synthesized the modified dPur $^{\mathbf{P}}$ TP triphosphate by application of the LudwigEckstein triphosphorylation conditions ${ }^{43-44}$ on the suitably 3'-O-Ac protected nucleoside 6 which was obtained by a sequential acetylation-detritylation protocol starting with the known nucleoside 4 (Scheme 1). ${ }^{41}$ 


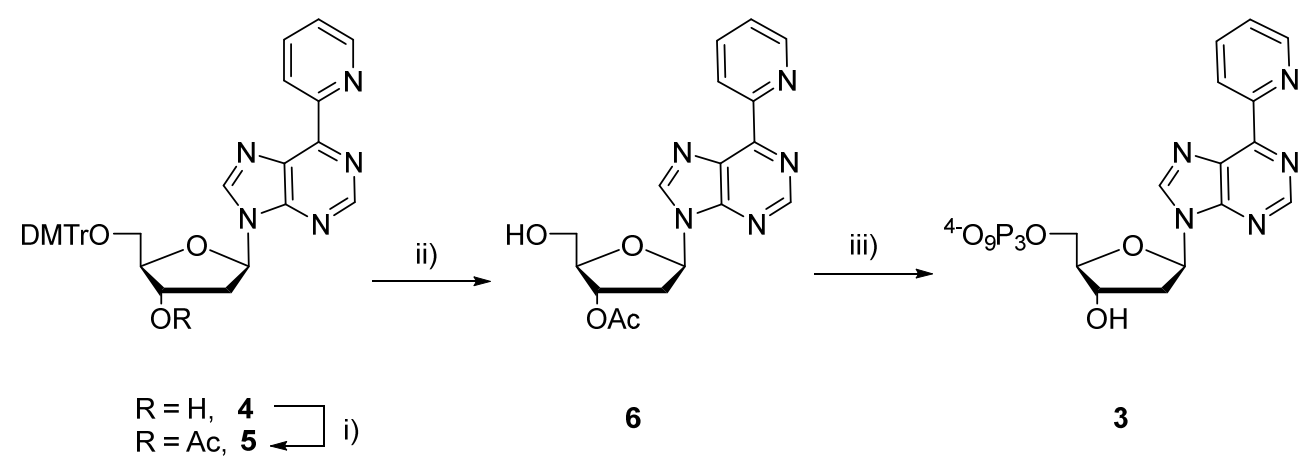

Scheme 1. Synthesis of $\mathbf{d P u r}^{\mathrm{P}} \mathbf{T P}$ 3. Reagents and conditions: (i) $\mathrm{Ac}_{2} \mathrm{O}, \mathrm{DMAP}_{\mathrm{NEt}}$, pyridine, $0^{\circ} \mathrm{C}, 1 \mathrm{~h}$; (ii) TCA 3\% in $\mathrm{CH}_{2} \mathrm{Cl}_{2}, \mathrm{CH}_{2} \mathrm{Cl}_{2}, \mathrm{rt}, 30 \mathrm{~min}, 70 \%$; (iii) 1. 2-chloro-1,3,2-benzodioxaphosphorin-4-one, pyridine, dioxane, rt, $45 \mathrm{~min} ; 2$. $\left(\mathrm{nBu}_{3} \mathrm{NH}\right)_{2} \mathrm{H}_{2} \mathrm{P}_{2} \mathrm{O}_{7}, \mathrm{DMF}, \mathrm{nBu} 3 \mathrm{~N}$, rt, 45 min; 3. $\mathrm{I}_{2}$, pyridine, $\mathrm{H}_{2} \mathrm{O}, \mathrm{rt}, 30$ min; 4. $\mathrm{NH}_{3}$ (aq.), rt, 2 h, $8 \%$ (4 steps).

The corresponding phosphoramidite building block for solid-phase synthesis of $\mathbf{d P u r} \mathbf{r}^{\mathbf{P}}$-containing DNA oligonucleotides was obtained by application of known literature procedures. ${ }^{45}$ All the templates containing modified nucleotides were obtained using automated solid-phase synthesis and are summarized in Table 1 . Template T1, containing a single $\mathbf{d P u r}^{\mathbf{P}}$ nucleotide located immediately after the 3'-end of the FAMlabelled primer $\mathbf{P 1}$ was synthesized to evaluate the possibility of forming the artificial metal base pairs dPur $^{\mathrm{P}}-\mathrm{M}^{\mathrm{n+}}-\mathbf{d P u r} \mathbf{r}^{\mathrm{P}}$ or $\mathbf{d I m} \mathbf{I m}^{\mathrm{C}}-\mathrm{M}^{\mathrm{n+}}-\mathbf{d P u r} \mathbf{r}^{\mathrm{P}}$ by enzymatic synthesis. In addition, the template $\mathbf{T} 2$ containing a $\mathbf{d I m}^{\mathbf{C}}$ nucleotide previously synthesized in our laboratory ${ }^{40}$ was used to study the formation of a $\mathbf{d P u r} \mathbf{r}^{\mathbf{P}}$ $\mathrm{M}^{\mathrm{n}+}-\mathbf{d} \mathbf{I m}^{\mathrm{C}}$ base pair.

Table 1. Sequences of the DNA primer and templates used for the primer extension reactions.

\begin{tabular}{lc}
\hline P1 & 5'-FAM-TAC GAC TCA CTA TAG CCT C \\
T1 & 5'-GGA GPur ${ }^{\mathbf{P}}$ G AGG CTA TAG TGA GTC GTA \\
T2 & 5'-GGA GIm ${ }^{\mathbf{C}}$ G AGG CTA TAG TGA GTC GTA \\
T3-T6 $^{\mathbf{a}}$ & 5'-GGA GNG AGG CTA TAG TGA GTC GTA \\
\hline $\mathbf{T 3}) ; \mathrm{N}=\mathrm{G}(\mathbf{T 4}) ; \mathrm{N}=\mathrm{A}(\mathbf{T} \mathbf{5}) ; \mathrm{N}=\mathrm{T}(\mathbf{T} \mathbf{6})$.
\end{tabular}

${ }^{\mathrm{a}} \mathrm{N}=\mathrm{C}(\mathbf{T 3}) ; \mathrm{N}=\mathrm{G}(\mathbf{T 4}) ; \mathrm{N}=\mathrm{A}(\mathbf{T 5}) ; \mathrm{N}=\mathrm{T}(\mathbf{T 6})$.

\section{Initial polymerase screen for the construction of $\mathrm{dPur}^{\mathrm{P}}-\mathrm{M}^{\mathrm{n}}-\mathrm{dPur} \mathrm{r}^{\mathrm{P}}$ and $\mathrm{dIm}^{\mathrm{C}}-\mathrm{M}^{\mathrm{n}}-\mathrm{dPur}{ }^{\mathrm{P}}$ base pairs}

The enzymatic construction of a $\mathbf{d P u r}^{\mathrm{P}}-\mathrm{M}^{\mathrm{n}+}-\mathbf{d P u r} \mathbf{r}^{\mathbf{P}}$ base pair, which involves the incorporation of $\mathbf{d P u r} \mathbf{r}^{\mathbf{P}} \mathbf{T P}$ opposite a templating $\mathbf{d P u r}^{\mathbf{P}}$ in the strict presence of a metal cation, was first evaluated with 5 different polymerases known to accept modified nucleotides ${ }^{18-19}$ (i.e. Bst, Deep Vent, Taq, Vent (exo-) and the Klenow 
fragment of DNA polymerase I exo- $\left(\mathrm{Kf}^{\left.\left(\mathrm{exo}^{-}\right)\right)}\right)$in the presence of 12 different metal cations (see the Supporting Information). First analysis of the primer extension (PEX) reactions using primer P1 and template $\mathbf{T} 1$ revealed the complete inefficacity of Deep Vent at recognizing the nucleotide as a substrate since only exonucleolytic degradation of the primer could be observed (data not shown). Similarly, Kf (exo) did not accept $\mathbf{d P u} \mathbf{r}^{\mathrm{P}} \mathbf{T P}$ as a substrate since no extension of the primer could be observed (Fig. S1). On the other hand, Bst and Vent ( $\left(x^{\circ}\right)$ polymerases permitted a full incorporation of the modified nucleotide but without any significant metal dependence (Fig. S1). The reactions catalysed by Taq led to the partial incorporation of the modified nucleotide in the presence of $\mathrm{Ag}^{\mathrm{I}}, \mathrm{Cu}^{\mathrm{II}}$ and $\mathrm{Mn}^{\mathrm{II}}$ but also to the incorporation of $\mathbf{d P u r}^{\mathbf{P}} \mathbf{M P}$ units in the absence of metal cations (Fig. S1), while all other PEX reactions conducted in presence of other metal cations only led to low yields of the $n+1$ product (Table S1). When we lowered the triphosphate concentration from $200 \mu \mathrm{M}$ down to $20 \mu \mathrm{M}$ in order to reduce misincorporation events in the absence of metal cofactors, no $\mathrm{n}+1$ product formation could be detected with Vent (exo-). However, the reactions performed with the Taq polymerase showed complete formation ( $91 \%$ yield) of the expected $n+1$ product when $\mathrm{Mn}^{\mathrm{II}}$ was added to the reaction mixture with clear cation dependence since very little incorporation could be observed with $\mathrm{Cu}^{\text {II }}$ (yield of $\mathrm{n}+1$ formation of $5 \%$ at $30 \mu \mathrm{M}, 6 \%$ at $60 \mu \mathrm{M}, 5 \%$ at $100 \mu \mathrm{M}) \mathrm{Ni}^{\mathrm{II}}$ or in the control reaction (yield of $6 \%$ ) (Fig. 2). While a number of metal ions such as $\mathrm{Cd}^{\mathrm{II}}$, $\mathrm{Ni}^{\mathrm{II}}, \mathrm{Cu}^{\mathrm{II}}$ or $\mathrm{Ga}^{\mathrm{III}}$ support polymerase activity, ${ }^{46-47}$ the addition of $\mathrm{Mn}^{\mathrm{II}}$ is known to relax the substrate specificity and the general polymerase fidelity and hence this result cannot be interpreted as the formation of a true $\mathbf{d P u r}^{\mathrm{P}}-\mathrm{Mn}^{\mathrm{II}}-\mathbf{d P u r}{ }^{\mathrm{P}}$ base pair. ${ }^{48-49}$

Reactions carried out with the $\mathrm{Kf}\left(\right.$ exo $\left.^{-}\right)$polymerase and $20 \mu \mathrm{M}$ of $\mathbf{d P u r}^{\mathbf{P}} \mathbf{T P}$ led to an efficient incorporation of the modified nucleotide when the reaction mixtures were supplied with $\operatorname{Ag}^{\mathrm{I}}$ (71\% yield of $\mathrm{n}+1$ product). The presence of silver cations seems to be required for the incorporation of $\mathbf{d P u r} \mathbf{r}^{\mathrm{P}} \mathbf{M P}$ units since only a small fraction of $n+1$ products can be detected in the control reaction carried out in the absence of metal cations (conversion yield of $13 \%$ ). Moreover, formation of the $n+1$ product appears to be selective with respect to the nature of the metal cation used since lower incorporation yields occurred with $\mathrm{Ni}^{\mathrm{II}}, \mathrm{Cd}^{\mathrm{II}}$ or $\mathrm{Fe}^{\mathrm{II}}$ especially at higher triphosphate concentrations (Fig. 2 and Fig. S2). Surprisingly, we did not observe the formation of $\mathrm{n}+1$ product under any of the experimental conditions that we tested when $\mathrm{Ni}^{\mathrm{II}}$ was included in the reaction mixtures (Fig. S2), even though this metal cation was shown to form very stable metal base pairs with short synthetic oligonucleotides. ${ }^{41}$ 


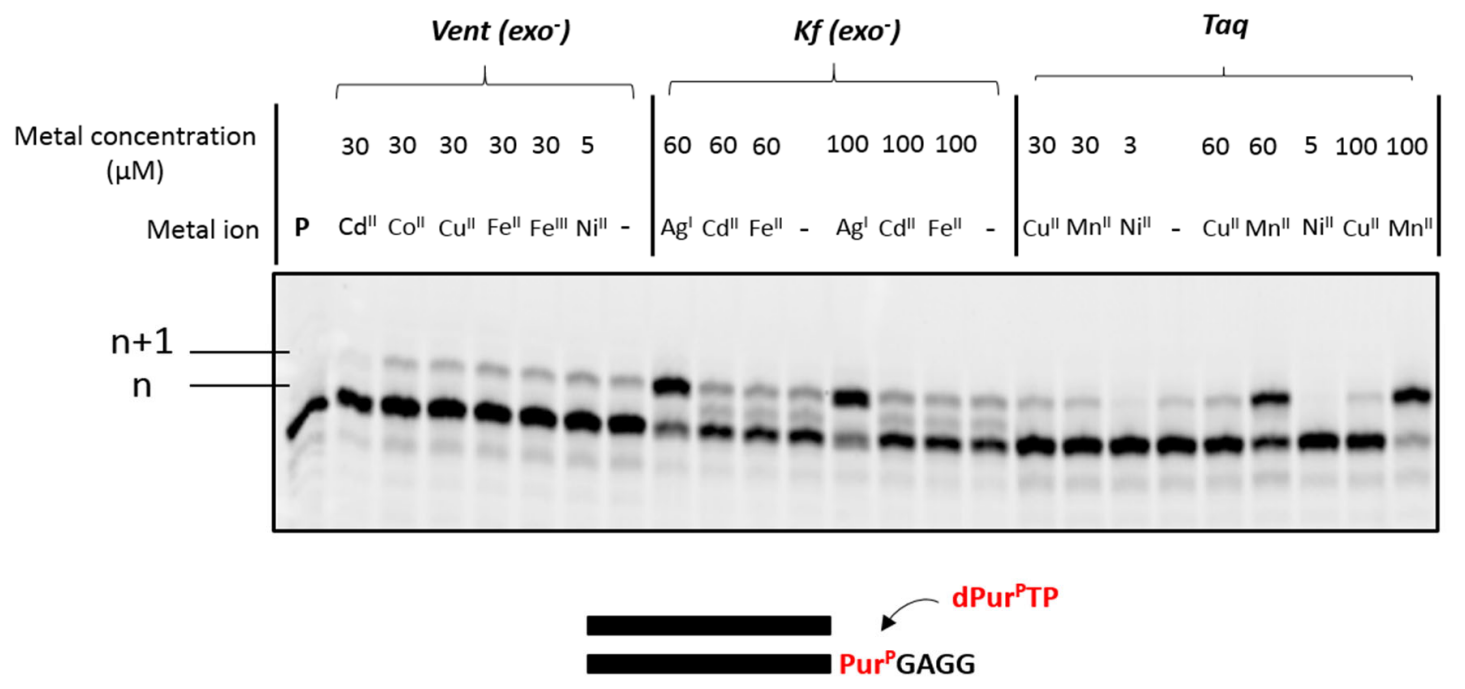

Figure 2. Gel analysis of the incorporation of $\mathbf{d P u r}^{\mathbf{P}} \mathbf{T P}(20 \mu \mathrm{M}$ final concentration) opposite a single

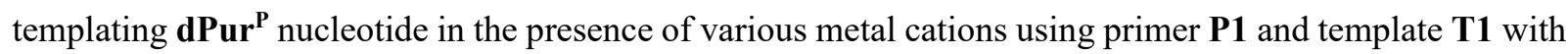
Vent $\left(\mathrm{exo}^{-}\right)(2 \mathrm{U}), \mathrm{Kf}\left(\mathrm{exo}^{-}\right)(5 \mathrm{U})$ and Taq polymerases $(5 \mathrm{U})$. Reaction mixtures were incubated at $60^{\circ} \mathrm{C}$ or $37^{\circ} \mathrm{C}$ for 1 hour. $\mathbf{P}$ indicates the unreacted primer. $\mathrm{Ag}^{\mathrm{I}}$ reaction conditions were performed with $\mathrm{AgNO}_{3}$ and $1 \mathrm{X}$ reaction buffer without any $\mathrm{Cl}^{-}$ions.

This initial screen revealed the capacity of $\mathrm{Kf}\left(\mathrm{exo}^{-}\right)$at incorporating a modified nucleotide opposite a templating $\mathbf{~ d P u r}^{\mathbf{P}}$ unit with $\sim 80 \%$ efficiency in the strict presence of $\mathrm{Ag}^{\mathrm{I}}$. We have previously shown ${ }^{40}$ that $\mathbf{d I m}^{\mathrm{C}}$ sustained the formation of artificial $\mathrm{Ag}^{\mathrm{I}}$-mediated base pairs under primer extension reaction (PEX) conditions and we therefore rationalized that $\mathbf{d I m}^{\mathrm{C}} \mathbf{T P}$ could be used instead of $\mathbf{d P u r} \mathbf{P}^{\mathrm{P}} \mathbf{T P}$ to further improve the specificity and yield of metal base pair formation.Consequently, we used the Vent (exo $)$ and $\mathrm{Kf}^{-}\left(\mathrm{exo}^{-}\right)$ polymerases in conjunction with 12 different metal cations to evaluate the possibility of forming $\mathbf{d I m}^{\mathrm{C}}-\mathrm{M}^{\mathrm{n}+}-$ dPur $^{\mathbf{P}}$ base pairs. PEX reactions were carried out with primer P1 and template $\mathbf{T 1}$ and revealed the formation of the expected $\mathbf{d I m}^{\mathrm{C}}-\mathrm{Ag}^{\mathrm{I}}-\mathbf{d P u r} \mathbf{r}^{\mathrm{P}}$ base pair for both polymerases and no incorporation of the modified nucleotide (i.e. yields $<10 \%$; Table S2) in the presence of any other metal cation or in the control reactions (Fig. S3). However, despite these promising results, the yield of formation of the extended product remained modest ( $\sim 50 \%$ conversion of the primer). We thus tried to optimize the reaction conditions in order to improve the yield of $n+1$ product formation (Fig. 3). In the case of Vent (exo $)$, the incorporation of $\mathbf{d I m}^{\mathrm{C}}$ MP opposite a templating $\mathbf{d P u r}^{\mathrm{P}}$ nucleotide does not seem to be dependent on the silver concentration as similar incorporation yields were obtained when the reactions were supplied with 60 and $30 \mu \mathrm{M} \mathrm{Ag}$. A 
slight improvement was observed when the reaction time was increased to 4 hours. For the $\mathrm{Kf}\left(\right.$ exo $\left.^{-}\right)$ polymerase, the yield of incorporation of the modified nucleotide was increased to $71 \%$ after 2 hours of incubation but the formation of $\mathrm{n}+1$ products could also be detected in the control reaction albeit to a lesser extent ( $25 \%$ conversion of the primer).

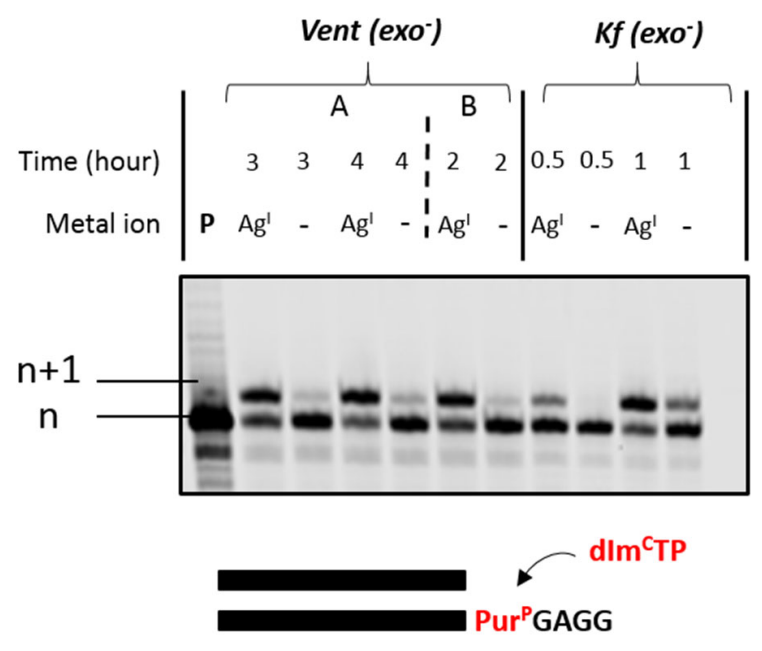

Figure 3. Gel analysis of the time dependence on the incorporation of $\mathbf{d I m}^{\mathrm{C}} \mathbf{T P}(20 \mu \mathrm{M}$ final concentration) opposite a single templating $\mathbf{d P u r}^{\mathbf{P}}$ in the presence of $\mathrm{Ag}^{\mathrm{I}}$ using primer $\mathbf{P} \mathbf{1}$ and template $\mathbf{T} 1$ with Vent (exo )$(2 \mathrm{U})$ and $\mathrm{Kf}\left(\right.$ exo $\left.^{-}\right)(5 \mathrm{U})$ polymerases. Mixtures were incubated at $60^{\circ} \mathrm{C}$ or $37{ }^{\circ} \mathrm{C}$ for different times. For Vent (exo ): A) $60 \mu \mathrm{M}$ of silver, B) $30 \mu \mathrm{M}$ of silver. For $\mathrm{Kf}\left(e x o^{\circ}\right): 30 \mu \mathrm{M}$ of silver. $\mathbf{P}$ indicates the unreacted primer. $\mathrm{Ag}^{\mathrm{I}}$ reaction conditions were performed with $\mathrm{AgNO}_{3}$ and $1 \mathrm{X}$ reaction buffer without any $\mathrm{Cl}^{-}$ions.

Taken together, this analysis revealed the higher propensity of the $\mathrm{Kf}\left(\mathrm{exo}^{-}\right)$polymerase at sustaining the enzymatic formation of the $\mathbf{d P u r}{ }^{\mathrm{P}}-\mathrm{Ag}^{\mathrm{I}}-\mathbf{d P} \mathbf{P r} \mathbf{r}^{\mathbf{P}}$ base pair and that of Vent $\left(e x o^{-}\right)$for the $\mathbf{d I m}^{\mathrm{C}}-\mathrm{Ag}^{\mathrm{I}}-\mathbf{d P} \mathbf{P} \mathbf{r}^{\mathbf{P}}$ base pair. Having identified conditions and polymerases that permit the formation of these artificial metal base pairs, we next sought to further optimize the reaction conditions to improve the yields of formation. Full conversion of the primer to the $\mathrm{n}+1$ product ( $86 \%$ yield) could be achieved when $\mathbf{d I m}^{\mathrm{C}} \mathbf{T P}$ was used in combination with Vent (exo'), long reaction times (up to 6h), and $60 \mu \mathrm{M} \mathrm{Ag}^{\mathrm{I}}$ (Fig. 4). For dPur ${ }^{\mathrm{P}} \mathbf{T P}$, up to $63 \%$ yields of $n+1$ product formation could be observed and the incorporation of the modified nucleotide was minimal in the absence of metal cations. Surprisingly, when modified triphosphate and modified template were inverted (i.e. using $\mathbf{d P u} \mathbf{r}^{\mathbf{P}} \mathbf{T P}$ as the incoming triphosphate and $\mathbf{d I m}^{\mathbf{C}}$ as the templating nucleotide) under the same experimental conditions, a $\mathbf{d I m}^{\mathbf{C}}-\mathbf{d P} \mathbf{\text { ur }} \mathbf{P}^{\mathbf{P}}$ mispair was formed irrespective of the presence and the nature of the metal cation (Fig. S4). 


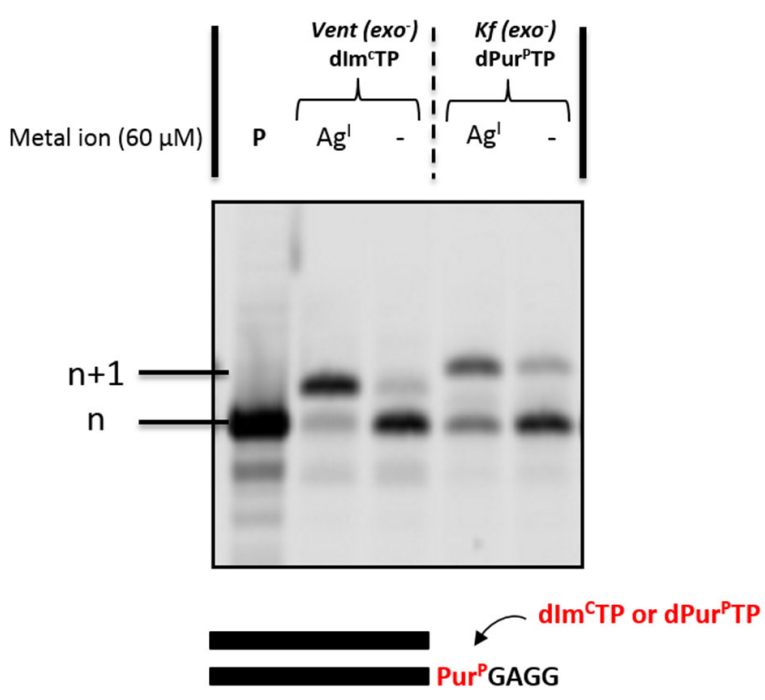

Figure 4. PAGE (20\%) analysis of the optimal conditions for the formation of a $\mathbf{d I m}^{\mathrm{C}}-\mathrm{Ag}^{\mathrm{I}}-\mathbf{d P u r} \mathbf{P}^{\mathrm{P}}$ base pair or $\mathbf{d P u r} \mathbf{P}^{\mathbf{P}}-\mathrm{Ag}^{\mathrm{I}}-\mathbf{d P u r}^{\mathbf{P}}$ in buffer 1 or buffer 2 , using the primer P1/template $\mathbf{T} 1$ system. For $\mathbf{d I m}^{\mathrm{C}} \mathbf{T P}$, the mixtures contained $2 \mathrm{U}$ of Vent (exo $)$ polymerase, $20 \mu \mathrm{M}$ final $\mathbf{d I m}^{\mathrm{C}} \mathbf{T P}$ and were incubated at $60{ }^{\circ} \mathrm{C}$ for 6 hours. For $\mathbf{d P u r}^{\mathbf{P}} \mathbf{T P}$, the mixtures contained $5 \mathrm{U}$ of $\mathrm{Kf}($ exo $)$ polymerase, $40 \mu \mathrm{M}$ final $\mathbf{d P u r}^{\mathbf{P}} \mathbf{T P}$ and were incubated at $37^{\circ} \mathrm{C}$ for $30 \mathrm{~min}$. $\mathbf{P}$ indicates unreacted primer.

\section{DFT calculations for modelling possible dPur ${ }^{\mathrm{P}}-\mathrm{Ag}^{\mathrm{I}}-\mathrm{dPur}{ }^{\mathrm{P}}$ and $\mathrm{dIm}^{\mathrm{C}}-\mathrm{Ag}^{\mathrm{I}}-\mathrm{dPur}^{\mathrm{P}}$ base pairs}

The above experimental findings clearly highlighted the formation of non-natural metal base pairs by homopairing between two $\mathbf{d P u r} \mathbf{r}^{\mathbf{P}}$ ligands and heteropairing between a $\mathbf{d P u r} \mathbf{r}^{\mathbf{P}}$ and a $\mathbf{d I m}^{\mathbf{C}}$ nucleotide in the presence of $\mathrm{Ag}^{\mathrm{I}}$ ions. However, we could not observe any formation of the $\mathbf{d P u r}^{\mathbf{P}}-\mathrm{Ni}^{\mathrm{II}}-\mathbf{d P u r} \mathbf{r}^{\mathbf{P}}$ base pair, although it had been previously reported with synthetic oligonucleotides in UV melting experiments. ${ }^{41} \mathrm{~A}$ similar observation was made previously with $\mathbf{d I m}^{\mathrm{C}}$ which forms stable $\mathbf{d} \mathbf{I m}{ }^{\mathrm{C}}-\mathrm{Cu}^{\mathrm{II}}-\mathbf{d} \mathbf{I} \mathbf{m}^{\mathrm{C}}$ base pairs with synthetic oligonucleotides in UV melting experiments ${ }^{26}$ and a $\mathbf{d} \mathbf{I m}^{\mathrm{C}}-\mathrm{Ag}^{\mathrm{I}}-\mathbf{d} \mathbf{I} \mathbf{m}^{\mathbf{C}}$ UBP under enzymatic conditions. ${ }^{40}$ Also, we were surprised by the fact that a simple inversion of the roles of $\mathbf{d P u r} \mathbf{r}^{\mathbf{P}}$ and $\mathbf{d I m} \mathbf{m}^{\mathbf{C}}$ nucleotides led to a completely different outcome during PEX reactions. This prompted us to carry out a DFT analysis in an attempt at rationalizing these findings. Indeed, quantum mechanics calculations are performed on systems involving short synthetic oligonucleotides ${ }^{50}$ to confirm the formation of metal base pairs as well as on canonical nucleic acids to further refine our understanding of base pair formation. ${ }^{51}$ Therefore, such an analysis was deemed to shed some light into these experimental findings. Thus, we first computationally modelled the possible base pairing geometries involving the homopairing of $\mathbf{d P u r} \mathbf{r}^{\mathbf{P}}$ bases mediated by $\mathrm{Ag}^{\mathrm{I}}$. Three possible base pair models were generated and optimized by DFT calculations, with the 'cis' relative orientation of their glycosidic bonds of the interacting nucleobases relative to the hydrogen 
bonds $^{52}$ : a canonical Watson-Crick like geometry (cWW-like), a Watson Crick-Hoogsteen like geometry (cWH-like, where a dPur ${ }^{\mathrm{P}}$ uses its Watson Crick edge, while the other one uses its Hoogsteen edge in a cis orientation of the glyosidic bond), and a Hoogsteen-Hoogsteen like geometry (cHH-like, where both the dPur $^{\mathbf{P}}$ bases use their Hoogsteen edges, see Fig. S6a). However, the default glycosidic bonds of the two nucleobases was assumed to be in an anti configuration. We carried out calculations in the presence of one or two coordinating $\mathrm{Ag}^{\mathrm{I}}$ cations, where the two metal cations are believed to be preferred, due to the coordination environment created by both modified nucleotides and to literature precedents. ${ }^{26,29,35,53}$

In case of a single $\mathrm{Ag}^{\mathrm{I}}$ cation, in the optimized cWW-like geometry of the $\mathbf{d P u r} \mathbf{r}^{\mathrm{P}}-\mathrm{Ag}^{\mathrm{I}}-\mathbf{d P u r} \mathbf{r}^{\mathbf{P}}$ pair, the distance between the $\mathrm{C} 1$ ' atoms of the nucleotides, which gives an indication of their isostericity (i.e. the geometrical equivalence) with natural base pairs ${ }^{54}$ is of $11.48 \AA$, that is only $0.88 \AA$ longer than the average value of dA:dT and dG:dC pairs (10.48 and $10.69 \AA$, respectively, see Fig. S5). For the cWH- and cHH-like geometries, it is instead of $9.02 \AA$ and $6.68 \AA$, i.e. shorter by $1.58 \AA$ and $3.92 \AA$, respectively, as compared to natural A:T/G:C pairs (see Fig. S6, b,c). Further, energy calculations showed that the cWW-like geometry is more stable by $6.9(5.0) \mathrm{kcal} / \mathrm{mol}$ and by $15.3(10.6) \mathrm{kcal} / \mathrm{mol}$ in gas phase (water) as compared to the cWH- and cHH-like geometries, respectively. It is to be remarked that the above geometries resulted from imposing a Cs symmetry during the geometry optimizations, in order to maintain the planarity of the pair. Using no symmetry constraints (a $\mathrm{C} 1$ symmetry) resulted indeed in non-planar geometries, possibly due to the electronic repulsion between $\mathrm{C} 2-\mathrm{H}$ on the purine moiety and the $\mathrm{C}-\mathrm{H}$ group of the pyridine moiety of the $\mathbf{d P u r}^{\mathbf{P}}$ bases facing each other (see Fig. S7). However, the optimized unconstrained $\mathbf{d P u r}^{\mathbf{P}}-\mathbf{A g}^{\mathrm{I}}-\mathbf{d P u r}^{\mathbf{P}}$ cWW base pair results to be only $4.91 \mathrm{kcal} / \mathrm{mol}$ less stable as compared to the constrained planar geometry. This small energy difference is expected to be easily compensated by the stacking interactions that the planar base pair can establish with adjacent bases in the DNA duplex and also by the energy gain due to absence of perturbation of adjacent base pair geometries. ${ }^{55} \mathrm{We}$ also tried to constrain the C1'-C1' distance of the cWW-like base pair to the ideal value of $10.6 \AA$ (averaged over the two canonical dA:dT/dG:dC base pairs). This resulted in a geometry that is only $2.02 \mathrm{kcal} / \mathrm{mol}$ less stable than the Cs symmetry constrained optimized relaxed pair, in the gas phase. The above analyses support the experimental finding that $\mathbf{d P u r} \mathbf{r}^{\mathbf{P}}$ $\mathrm{Ag}^{\mathrm{I}}-\mathbf{d P u r} \mathbf{r}^{\mathbf{P}}$ base pairs can be readily formed in a geometry that perfectly fits a regular DNA duplex.

Then, we modelled the $\mathbf{d P u r} \mathbf{r}^{\mathrm{P}}-\mathrm{Ag}^{\mathrm{I}}-\mathbf{d} \mathbf{I m}^{\mathrm{C}}$ base pair. The gas-phase optimized model structure is shown in Fig. S6d. The resulting C1'-C1' distance is $11.79 \AA$, that is $\sim 1.2 \AA$ longer than in canonical base pairs. Interestingly, also in the absence of symmetry constraints ( $\mathrm{C} 1$ symmetry), no significant structural deformation is observed for the $\mathbf{d P u r} \mathbf{P}^{\mathrm{P}}-\mathrm{Ag}^{\mathrm{I}}-\mathbf{d} \mathbf{I m}^{\mathrm{C}}$ geometry, which remains substantially planar. The energy difference between the Cs symmetry constrained and unconstrained base pair geometries is indeed negligible and amounts to $0.06 \mathrm{kcal} / \mathrm{mol}$. Fixing the $\mathrm{C} 1$ '-C1' distance to the ideal value of $10.60 \AA$ results in 
an energy loss of $3 \mathrm{kcal} / \mathrm{mol}$. Both optimized geometries and energetics also support the successful formation of $\mathbf{d P u r} \mathbf{r}^{\mathrm{P}}-\mathrm{Ag}^{\mathrm{I}}-\mathbf{d} \mathbf{I m}^{\mathrm{C}}$ base pairs with a duplex-compatible geometry.

In order to rationalize the difference observed when $\mathbf{d P u r}^{\mathbf{P}}$ served as the incoming triphosphate from when it is integrated in the template, we considered two possible pathways for the formation of the $\mathbf{d P u r} \mathbf{r}^{\mathrm{P}}-\mathrm{Ag}^{\mathrm{I}}-$ $\mathbf{d I m}^{\mathrm{C}}$ heterobase pair (see Fig. 5). In the former case, the base pairing energies were computed under the assumption that the bidentate $\mathbf{d P u r}^{\mathbf{P}}$ ligand binds to the $\mathrm{Ag}^{\mathrm{I}}$ ion first, leading to the formation of $\mathbf{d P u r} \mathbf{P}_{-}$ $\mathrm{Ag}^{\mathrm{I}}$, with the subsequent addition of the $\mathbf{d I m}^{\mathrm{C}}$ ligand, resulting in the $\mathbf{d P u} \mathbf{r}^{\mathrm{P}}-\mathbf{A g}^{\mathrm{I}}-\mathbf{d} \mathbf{I m}^{\mathbf{C}}$ complex (Scheme 1 in Fig. 5). In the latter modelled pathway, a bidentate $\mathbf{d I m}^{\mathrm{C}}$ binds first to $\mathrm{Ag}^{\mathrm{I}}$, leading to the formation of $\mathbf{d I m}^{\mathrm{C}}-\mathrm{Ag}^{\mathrm{I}}$, with the subsequent addition of the $\mathbf{d P u r} \mathbf{r}^{\mathrm{P}}$ ligand, resulting in the same $\mathbf{d P u} \mathbf{r}^{\mathbf{P}}-\mathrm{Ag}^{\mathrm{I}}-\mathbf{d I m}^{\mathbf{C}}$ complex (Scheme 2 in Fig. 5). Our energy calculations indicate that silver-mediated base pair formation seems to be favourable for both modelled reactions (see Table S3). However, the former pathway is clearly favoured over the latter one with an energy difference of $90.5 \mathrm{kcal} / \mathrm{mol}$ and $3.6 \mathrm{kcal} / \mathrm{mol}$ in the gas phase and in water, respectively. Hence, metal coordination to $\mathbf{d P u r}^{\mathbf{P}}$ appears to be the first step required for metal base pair formation which occurs preferentially when this analogue serves as a templating nucleotide. While this analysis does not fully explain the preference that was observed, it clearly demonstrates that metal coordination to the templating nucleotide is an important prerequisite for and an important first step in the formation of artificial metal base pairs under polymerase-mediated synthesis conditions.

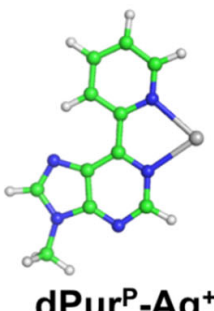

dPurP-Ag+

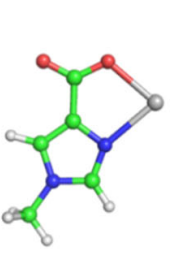

$\mathrm{Im}^{\mathrm{C}}-\mathrm{Ag}^{+}$
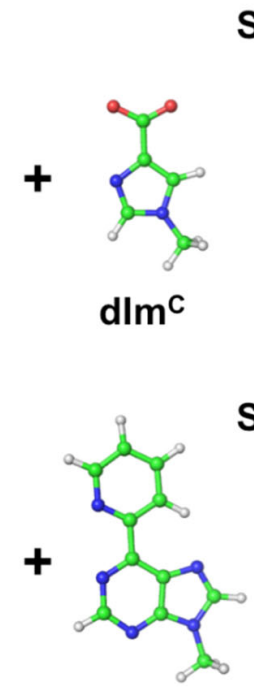

dPur ${ }^{P}$

\section{Scheme 1}

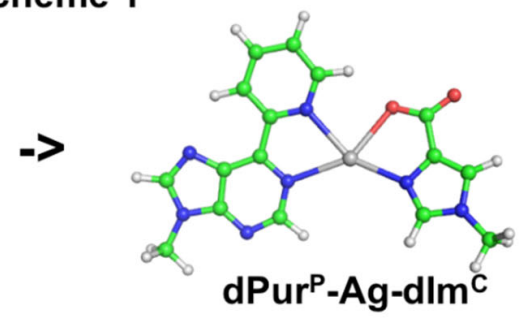

Scheme 2

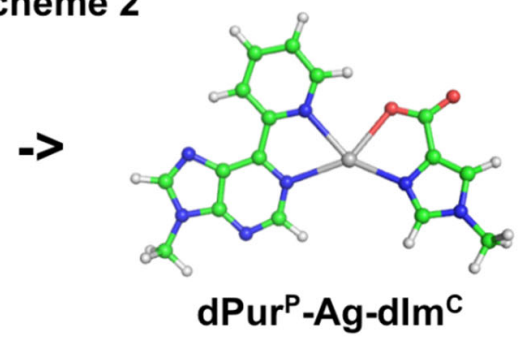

Figure 5: Formation of $\mathbf{d P u r}^{\mathbf{P}}-\mathrm{Ag}^{\mathrm{I}}-\mathbf{d I} \mathbf{m}^{\mathrm{C}}$ complex followed by two possible pathways depicted in Scheme 1 and Scheme 2. 
As mentioned above, in addition to the mononuclear $\mathrm{Ag}^{\mathrm{I}}$ mediated base pairs, we have also investigated the above base pair geometries mediated by two coordinating $\mathrm{Ag}^{\mathrm{I}}$ ions (Fig. 6 a-d).

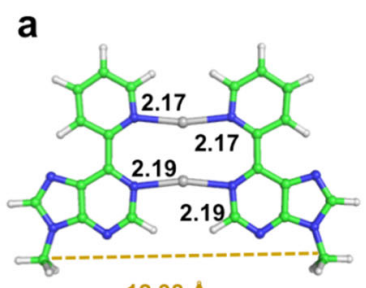

$12.38 \mathrm{~A}$

dPur ${ }^{\mathrm{P}}-\mathrm{AAg}^{+}-\mathrm{dPur}^{\mathrm{P}}$ cWW-like b

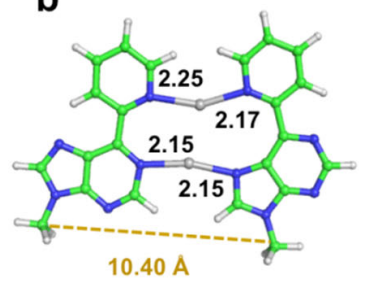

$\mathrm{dPur}^{\mathrm{P}}-2 \mathrm{Ag}^{+}-\mathrm{dPur}^{\mathrm{P}}$ cWH-like

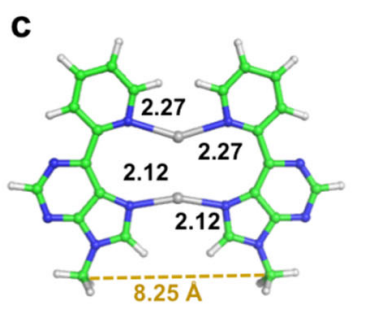

dPur ${ }^{\mathrm{P}}-2 \mathrm{Ag}^{+}-\mathrm{dPur}^{\mathrm{P}} \mathrm{cHH}-\mathrm{like}$

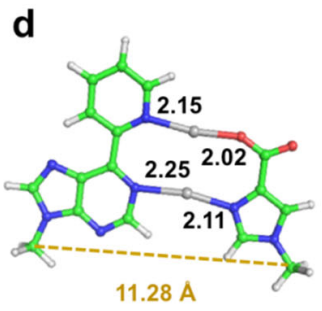

dPur ${ }^{\mathrm{P}}-\mathbf{2} \mathrm{Ag}^{+}-\mathrm{dlm}^{\mathrm{C}}$

Figure 6. a-d) Optimized $\mathbf{d P u r}^{\mathrm{P}}-2 \mathrm{Ag}^{\mathrm{I}}-\mathbf{d P u r}^{\mathbf{P}}$ base pairs in different geometries: cWW like (a), cWH like (b) and $\mathrm{cWH}$ like (c). d) Optimized structure of the $\mathbf{d P u r} \mathbf{r}^{\mathrm{P}}-2 \mathrm{Ag}^{\mathrm{I}}-\mathbf{d I m}^{\mathbf{C}}$ base pair. Optimal distances in gas phase of the key atoms from the coordinated $\mathrm{Ag}^{\mathrm{I}}$ ion are reported. $\mathrm{C} 1$ '-C1' distances are also shown for all the base pairs. $\mathrm{A}_{\mathrm{s}}$ symmetry constraint was imposed during the geometry optimizations to retain planarity.

For the $\mathbf{d P u r}^{\mathrm{P}}$ homopairing, our modeling studies show that the insertion of an additional $\mathrm{Ag}^{\mathrm{I}}$ ion increases the $\mathrm{C}^{1}-\mathrm{C} 1$ ' distances, as compared to the corresponding mono $\mathrm{Ag}^{\mathrm{I}}$ mediated base pairs, for all the geometries (by $0.90 \AA, 1.38 \AA$ and $1.57 \AA$ for cWW-, cWH- and cHH-like geometries, respectively, see Fig. 6a-c). As a consequence, the $\mathbf{d P u r}^{\mathrm{P}}-2 \mathrm{Ag}^{\mathrm{I}}-\mathbf{d P u r} \mathbf{r}^{\mathrm{P}}$ cWH-like geometry, with a C1'-C1' distance of $10.40 \AA$, results to be highly isosteric to the canonical A:T/G:C base pairs (10.48/10.69 $\AA)$. As for the energies, the dinuclear $\mathrm{Ag}^{\mathrm{I}}$ mediated base pairs are less stable than the mononuclear $\mathrm{Ag}^{\mathrm{I}}$ mediated ones by 1.38, 2.41 and $6.83 \mathrm{kcal} / \mathrm{mol}$ for the $\mathrm{cWW}-$, cWH- and $\mathrm{cHH}$-like geometries in the gas phase. When the pairing of $\mathbf{d P u r} \mathbf{P}^{\mathbf{P}}$ with $\mathbf{~ I I m}^{\mathrm{C}}$ is considered; its $\mathrm{C} 1$ '-C1' distance gets shortened by $0.51 \AA$ as a consequence of the coordination of the second $\mathrm{Ag}^{\mathrm{I}}$ cation, thus getting closer to the canonical $10.6 \AA$ distance. Furthermore, the pairing appears to be more stable than in the case of the mono $\mathrm{Ag}^{\mathrm{I}}$ coordinated base pair by $77.35 \mathrm{kcal} / \mathrm{mol}$ and $10.48 \mathrm{kcal} / \mathrm{mol}$ in the gas phase and in water, respectively. Lastly, calculations carried out in the absence of $\mathrm{Ag}^{\mathrm{I}}$ suggest the possible formation of weak H-bonding pairing between $\mathbf{d P u r}^{\mathbf{P}}$ with $\mathbf{d I m}^{\mathrm{C}}$ (Fig. S9) which might account for some results observed during our initial polymerase screen where complete formation of the $n+1$ product was observed even in the absence of metal cations with the Taq polymerase (Fig. S1).

Taken together, our analyses of geometries and energies suggest that both the single and the dinuclear $\mathrm{Ag}^{\mathrm{I}}$ coordination modes are in principle possible for the homopairing between $\mathbf{d P u r}^{\mathbf{P}}$ bases. However, both for 
energetic and geometrical reasons the $\mathrm{cWW}$ - and $\mathrm{cWH}$-like geometries seem to be favored over the cHHlike ones. As for the heteropairing between $\mathbf{P u r}^{\mathbf{P}}$ and $\mathbf{I m}^{\mathrm{C}}$, it seems to be favored both energetically and geometrically in the presence of a second coordinating $\mathrm{Ag}^{\mathrm{I}}$ ion.

\section{By-pass experiments}

Having established conditions that permit the enzymatic construction of a $\mathbf{d I m}^{\mathbf{C}}-\mathrm{Ag}^{\mathrm{I}}-\mathbf{d P} \mathbf{u r}^{\mathbf{P}}$ base pair we next assessed whether enzymatic DNA synthesis could be resumed with canonical nucleotides after the construction of the metal base pair. By-passing a UBP is crucial required for the construction of modified libraries with view of their use in selection experiments but also for the general construction of modified oligonucleotides. ${ }^{56-58}$ To do so, we first installed a $\mathbf{d I m}^{\mathrm{C}}-\mathrm{Ag}^{\mathrm{I}}-\mathbf{d P u} \mathbf{r}^{\mathrm{P}}$ base pair by PEX reaction using the P1/T1 system and the experimental conditions described in Fig. 4. After addition of the four canonical dNTPs, only one additional $\mathrm{dC}$ nucleotide was incorporated immediately after the artificial metal base pair and DNA synthesis halted at this stage (Fig. S8a). We first thought that the inability of the polymerase to further extend the primer might be ascribed to the presence of remaining $\mathrm{Ag}^{\mathrm{I}}$ in the reaction mixture, which could disturb the formation of natural base pairs. Therefore, we added 1.2 equivalents of $\mathrm{NaCl}$ or EDTA after the formation of the $\mathbf{d I m}^{\mathrm{C}}-\mathrm{Ag}^{\mathrm{I}}-\mathbf{d P u r} \mathbf{r}^{\mathrm{P}}$ base pair and prior to the addition of natural dNTPs but this had no positive impact on the bypass efficiency (Fig. S8b). We next conducted bypass experiments using the more permissive polymerase Therminator ${ }^{59-60,61}$ which is known to recognize UBPs. ${ }^{62}$ Under these conditions, the formation of the $n+6$ product was observed by gel electrophoresis (Fig. 7) which corresponds to the expected full length sequence with an additional nucleotide stemming from a non-templated addition, showing that the $\mathbf{d I m}^{\mathrm{C}}-\mathrm{Ag}^{\mathrm{I}}-\mathbf{d P u r}{ }^{\mathrm{P}}$ base pair can efficiently be by-passed by the Therminator polymerase ( $68 \%$ formation of the $\mathrm{n}+6$ product). To exclude the formation of any mispairs (especially dG:dT pairs) by the error prone Therminator polymerase and to confirm the identity of the formed product, an LC-MS analysis was performed. To do so, we first conducted by-pass experiments with a 5'-phosphorylated template T1 (obtained by PNK treatment of T1), subjected the resulting dsDNA product to a $\lambda$-exonucleasemediated degradation, and analyzed the ssDNA product by LC-MS (Fig. S19 and Fig. S20). This analysis univocally proved the formation of the expected full length product and further confirmed the untemplated addition of an additional dA nucleotide, which has previously been observed with Therminator (Fig. S20). ${ }^{61,}$ ${ }^{63}$ Thus, this represents a convenient method for the synthesis of DNA duplexes containing a $\mathbf{d I m} \mathbf{m}^{\mathrm{C}}-\mathrm{Ag}^{\mathrm{I}}-$ dPur ${ }^{\mathrm{P}}$ UBP. 


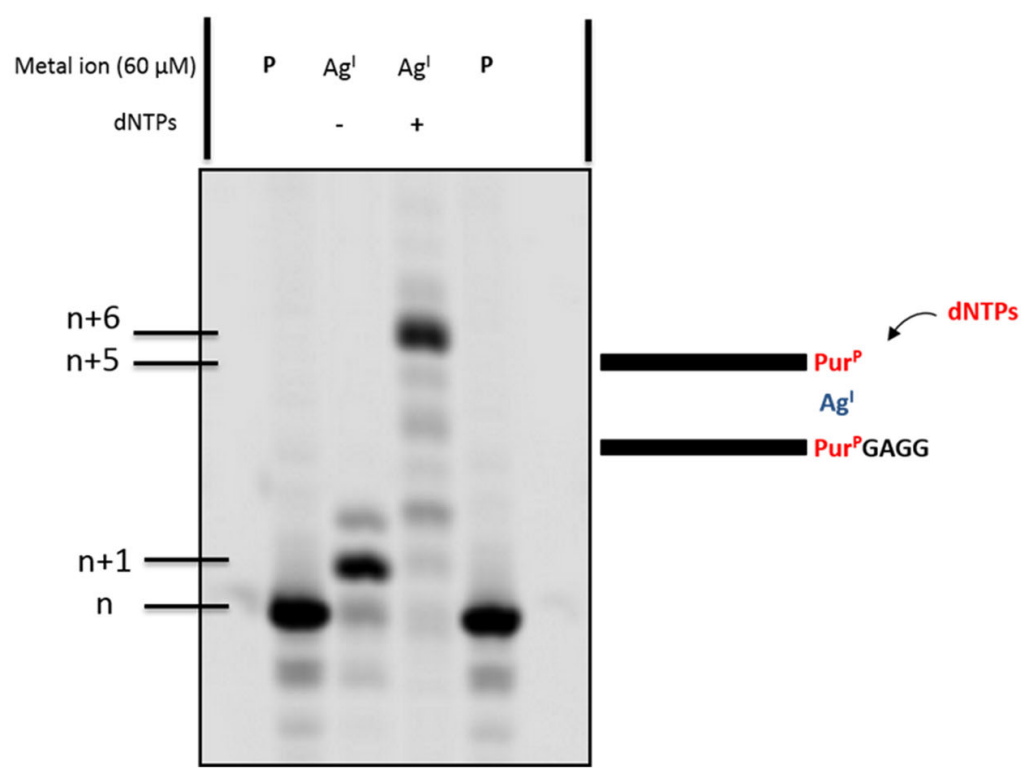

Figure 7. Gel (PAGE 20\%) image analysis of the modified base pair by-pass experiments. All the reactions were carried out with primer P1 and phosphorylated template T1 and first incubated in the presence of $\mathbf{d I m}^{\mathrm{C}} \mathbf{T P}(20 \mu \mathrm{M})$ and $2 \mathrm{U}$ of Vent $($ exo $)$ polymerase at $60^{\circ} \mathrm{C}$ for $6 \mathrm{~h}$. dNTPs $(20 \mu \mathrm{M})$ were added with 10 $\mathrm{U}$ of Therminator polymerase and incubated at $60^{\circ} \mathrm{C}$ for $30 \mathrm{~min} . \mathbf{P}$ indicates unreacted primer.

\section{Specificity of the incorporation}

Next, we sought to determine the specificity of the incorporation of canonical dNTPs opposite a templating dPur $^{\mathbf{P}}$ nucleotide and conversely the specificity of the incorporation of the modified triphosphate $\mathbf{A P u r} \mathbf{P}^{\mathbf{P}} \mathbf{T P}$ opposite wild-type nucleotides. These experiments are important to evaluate the possibility of using the $\mathbf{d I m}^{\mathrm{C}}-\mathrm{Ag}^{\mathrm{I}}-\mathbf{d P u r}^{\mathrm{P}}$ base pair system in SELEX experiments, specifically in the PCR amplification and sequencing steps. For both Vent $\left(e x o^{-}\right)$and $\mathrm{Kf}\left(e x o^{-}\right)$polymerases, we carried out primer extension reactions with template T1 and each individual dNTP, in the presence and absence of silver ions (Fig. 8). Even though synthetic duplexes were shown to be strongly destabilized in the presence of $\mathbf{d P u r} \mathbf{r}^{\mathbf{P}}$ mismatches with all the natural bases, ${ }^{41}$ the efficient incorporation of a dT nucleotide opposite $\mathbf{~ d P u r}^{\mathbf{P}}$ was observed with both polymerases. Yet, more surprisingly, Vent $\left(\mathrm{exo}^{-}\right)$misincorporated dA opposite the modification with around $35 \%$ yield of the $\mathrm{n}+1$ product regardless on the presence or absence of $\mathrm{Ag}^{\mathrm{I}}$ (38\% yield without addition of silver, $32 \%$ yield in the presence of silver). In addition, $n+1$ and $n+2$ products can also be observed with dCTP corresponding to the formation of $\mathrm{dC}^{-\mathbf{d P u r}} \mathbf{P}^{\mathbf{P}}$ and $\mathrm{dC}^{-}-\mathrm{Ag}^{\mathrm{I}}-\mathbf{d P u r}^{\mathbf{P}}$ mispairs. The latter was not unexpected since silver is known to mediate the formation of dC-Ag $-\mathrm{dA}$ base pairs. ${ }^{64}$ When Vent (exo-) was used in PEX reactions, misincorporation of dG opposite the modification occurred at much lower levels 
than with $\mathrm{dC}, \mathrm{dA}$, and $\mathrm{dT}$ regardless on the presence or absence of $\mathrm{Ag}^{\mathrm{I}}$. In the case of the $\mathrm{Kf}($ exo- $)$ polymerase, while $\mathrm{dC}$ ( $6 \%$ incorporation with or without silver) or $\mathrm{dG}(6 \%$ incorporation with or without silver) nucleotides are not misincorporated opposite $\mathbf{d P u r}{ }^{\mathbf{P}}$, dAMP units are efficiently incorporated with or without $\mathrm{Ag}^{\mathrm{I}}(80 \% \mathrm{n}+1$ product formation without silver and $75 \%$ with silver $)$.

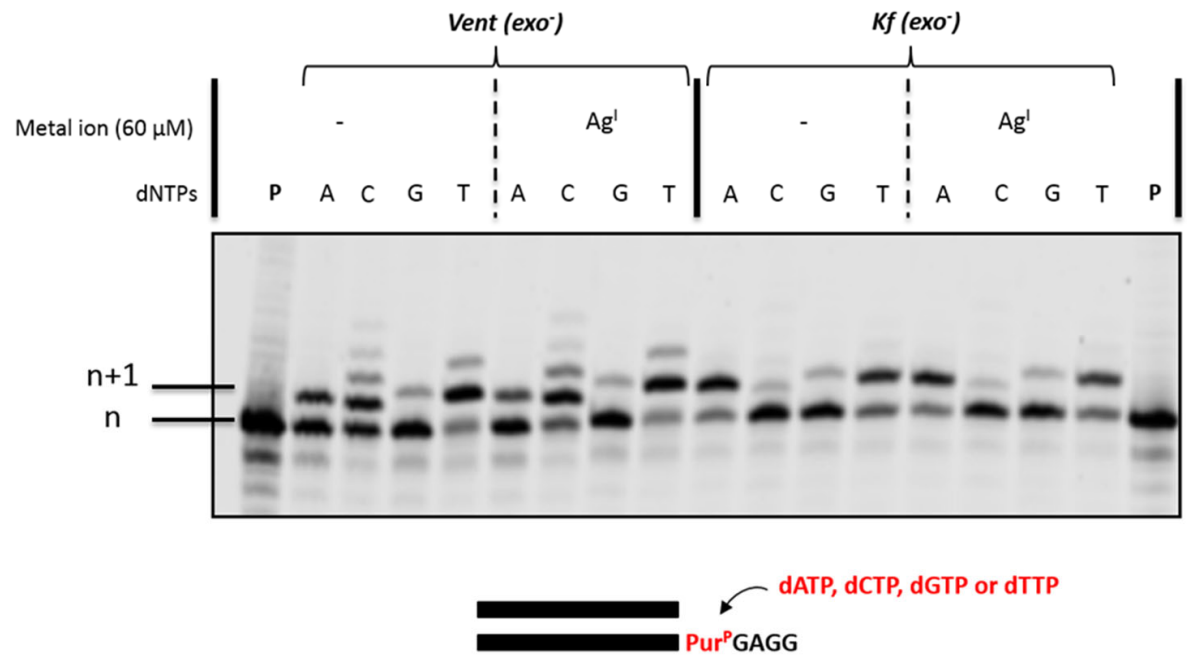

Figure 8. Extension reactions of the $\mathbf{d P u r} \mathbf{r}^{\mathbf{P}}$ containing template $\mathbf{T} 1$ with each individual dNTP. All reactions were conducted using the primer P1 and Vent (exo ) (2 U) or Kf (exo ) (5 U) polymerase. The reaction mixtures contained natural dNTPs $\left(200 \mu \mathrm{M}\right.$ final concentration) and were incubated for $30 \mathrm{~min}$ at $60^{\circ} \mathrm{C}$ or $37^{\circ} \mathrm{C}$. $\mathbf{P}$ indicates unreacted primer.

In order to investigate the specificity of the incorporation of $\mathbf{d P u r}{ }^{\mathbf{P}} \mathbf{T P}$, we carried out PEX reactions using templates T3-T6 (Table 1) that contain each one of the canonical bases at the site of the modification in T1. This analysis clearly revealed that $\mathbf{d P u r}{ }^{\mathbf{P}} \mathbf{M P}$ was readily incorporated opposite templating $\mathrm{dC}$ and $\mathrm{dT}$ nucleotides by the Vent ( $\mathrm{exo}^{-}$) polymerase, even in the absence of silver cations. A partial incorporation of the modified nucleotide opposite dG was also observed (Fig. 9). The presence of silver seemed to inhibit the incorporation of $\mathbf{d P u r}^{\mathrm{P}} \mathbf{T P}$ opposite a dA nucleotide as $81 \%$ incorporation occurred in the absence of $\mathrm{Ag}^{\mathrm{I}}$, compared to $63 \%$ incorporation in its presence. For the $\mathrm{Kf}\left(\right.$ exo $\left.^{-}\right)$polymerase, partial incorporation of the modified nucleotide was detected opposite $\mathrm{dA}$ and $\mathrm{dG}$ in the absence of $\mathrm{Ag}^{\mathrm{I}}$ but not opposite the other two canonical nucleotides. Addition of $\mathrm{Ag}^{\mathrm{I}}$ seems to negatively affect the incorporation opposite a dA nucleotide but to favor the formation of base pairs with $\mathrm{dC}, \mathrm{dG}$ and $\mathrm{dT}$. Therefore, the incorporation of dPur $^{\mathbf{P}}$ MPs does not exclusively occur when the templating nucleotide is $\mathbf{d P u r}^{\mathbf{P}}$ since misincorporation events are observed. 


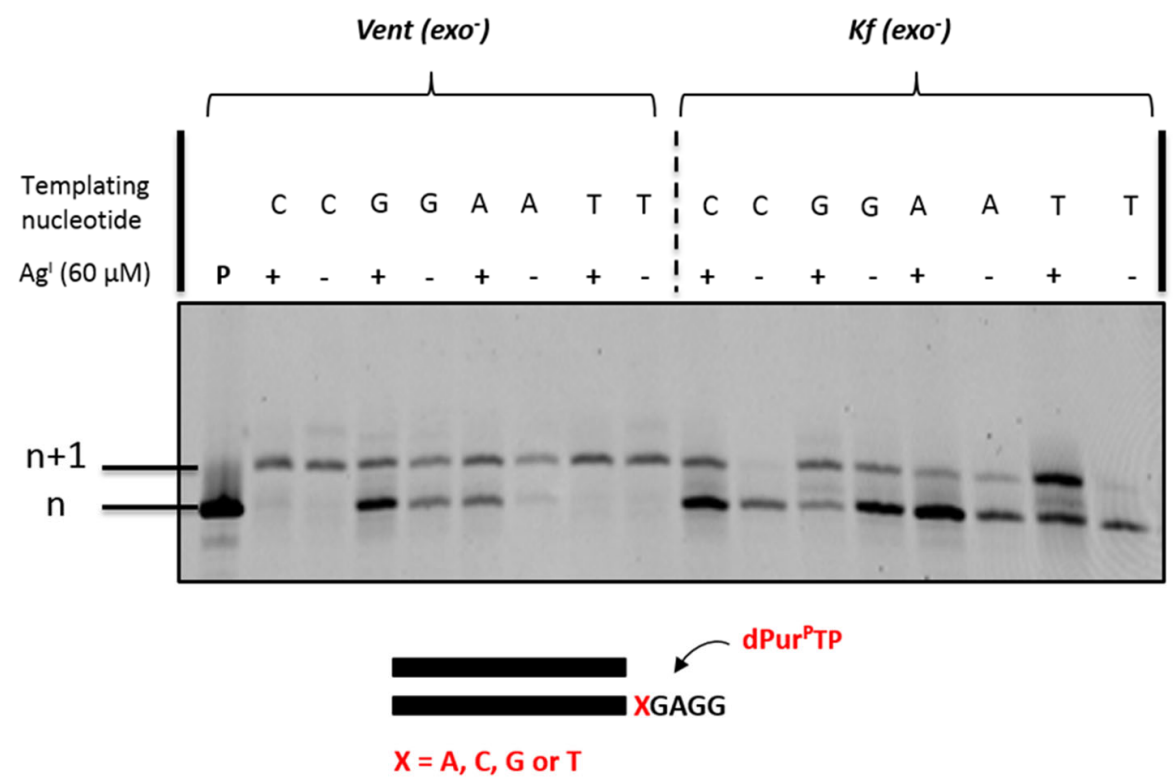

Figure 9. PEX reactions with $\mathbf{d P u r}^{\mathrm{P}} \mathbf{T P}$ modified nucleotide using the templates T3-T6 and Vent (exo-) (2 $\mathrm{U})$ or $\mathrm{Kf}\left(e x o^{-}\right)(5 \mathrm{U})$ as polymerases. The reaction mixtures contained $\mathbf{d P u r}^{\mathrm{P}} \mathbf{T P}$ at $20 \mu \mathrm{M}$ final concentration and were incubated for $30 \mathrm{~min}$ at $60^{\circ} \mathrm{C}$ or $37^{\circ} \mathrm{C}$. $\mathbf{P}$ indicates unreacted primer.

\section{DFT calculations for modelling the mispairs of $\mathrm{dPur}^{\mathrm{P}}$ and canonical nucleobases}

UV melting experiments performed on dodecamers containing a single $\mathbf{d P u r} \mathbf{r}^{\mathbf{P}}$ modification have shown that mismatches between $\mathbf{d P u r}^{\mathbf{P}}$ and canonical nucleotides led to strong destabilization of the resulting duplexes. However, PEX reactions indicated that $\mathbf{d P u r}^{\mathbf{P}}$ nucleotides (both as incoming triphosphate or templating nucleotide) misincorporated particularly well opposite canonical $\mathrm{dT}$. In order to try to rationalize these findings we modelled pairing of $\mathbf{d P u r}^{\mathbf{P}}$ with the four natural nucleobases, with and without the $\mathrm{Ag}^{\mathrm{I}}$ ion coordination. As the $\mathrm{Ag}^{\mathrm{I}}$ coordination is well known to occur with the nitrogen atoms of the heterocycles for both the natural and unnatural bases, in our modelling study we assumed the coordination to occur at the Watson-Crick edge of all the bases and, in addition, at the Hoogsteen edge of A and G (to N7) (cWH-like geometries, Fig. 10).

The $\mathrm{C} 1$ '-C1' distances of the possible $\mathrm{Ag}^{\mathrm{I}}$ mediated base pairs are larger than the average $\mathrm{C} 1$ '-C1' distance of canonical dA:dT/dG:dC base pairs for the $\mathbf{d P u r}^{\mathrm{P}}-\mathrm{Ag}^{\mathrm{I}}-\mathrm{dA}$ and $\mathbf{d P u r} \mathbf{r}^{\mathrm{P}}-\mathrm{Ag}^{\mathrm{I}}-\mathrm{dT}$ base pairs (by $1.8 \AA$ and 1.5 $\AA$, respectively) and shorter by $0.9 \AA$ for the $\mathbf{d P u r}{ }^{\mathrm{P}}-\mathrm{Ag}^{\mathrm{I}}-\mathrm{dC}$ base pair. For the $\mathbf{d P u r} \mathbf{r}^{\mathrm{P}}-\mathrm{Ag}^{\mathrm{I}}-\mathrm{dG}$ base pair, an elongation of the $\mathrm{C} 1$ '-C1' distance by $4.35 \AA$ is observed, which may be considered incompatible with a regular DNA duplex. However, considering the $\mathrm{Ag}^{\mathrm{I}}$ coordination to the $N 7$ of the $\mathrm{A}$ and $\mathrm{G}$ bases, in their 
cWH-like geometries, the $\mathrm{Cl}^{\prime}-\mathrm{C} 1^{\prime}$ distance of the $\mathbf{d P u r}^{\mathrm{P}}-\mathrm{Ag}^{\mathrm{I}}-\mathrm{dG}$ pair gets elongated by $1.1 \AA$, while it is extremely similar $(10.74 \AA)$ to the canonical A:T/G:C pairs for $\mathbf{d P u r}^{\mathrm{P}}-\mathrm{Ag}^{\mathrm{I}}-\mathrm{dA}$. Regarding energies, except for the $\mathbf{d P u r}^{\mathrm{P}}-\mathrm{Ag}^{\mathrm{I}}-\mathrm{dC}$ cWW-like pair, which is more stable than the corresponding $\mathbf{d P u r}^{\mathbf{P}}-\mathrm{Ag}^{\mathrm{I}}-\mathbf{d P u r} \mathbf{r}^{\mathbf{P}}$ pair (by 0.64 and $2.97 \mathrm{kcal} / \mathrm{mol}$ in the gas phase and in water, respectively), all the other $\mathrm{Ag}^{\mathrm{I}}$ mediated pairs between $\mathbf{d P u r}^{\mathbf{P}}$ and the Watson-Crick edge of the natural nucleobases are less stable, with energy differences within $16.27 \mathrm{kcal} / \mathrm{mol}$ and $9.28 \mathrm{kcal} / \mathrm{mol}$ in the gas phase and in water, respectively. However, looking at the $\mathrm{cWH}$ geometries, the $\mathbf{d P u r} \mathbf{r}^{\mathrm{P}}-\mathrm{Ag}^{\mathrm{I}}-\mathrm{dA}$ pair is further destabilized as compared to the $\mathrm{CWW}$-like geometry (by $3.55 / 1.56 \mathrm{kcal} / \mathrm{mol}$ in gas phase/water). On the contrary, the $\mathbf{d P u r}^{\mathrm{P}}-\mathrm{Ag}^{\mathrm{I}}-\mathrm{dG} \mathrm{cWH}$-like pair results more stable than the corresponding cWW-like geometry (by 16.2/11.0 kcal/mol in gas phase/water), also due to the formation of an additional weak H-bonding interaction (see Fig. 10a).

The high stability (and isostericity) of the dPur ${ }^{\mathrm{P}}-\mathrm{Ag}^{\mathrm{I}}-\mathrm{dC} \mathrm{cWW}$-like pair observed in this DFT analysis is reflected in PEX reactions conducted with the $\mathrm{Kf}\left(e^{-}\right)$polymerase since, when $\mathbf{d P u r}^{\mathbf{P}}$ acts as an incoming triphosphate, formation of the mispair is only observed in the presence of $\mathrm{Ag}^{\mathrm{I}}$ (Fig. 9). However, the formation of the $\mathbf{d P u r}^{\mathrm{P}}-\mathrm{Ag}^{\mathrm{I}}-\mathrm{dC}$ pair could not be observed ( $<5 \%$ product formation) when the modified nucleotide was incorporated in the template (Fig. 8). On the other hand, the incorporation events mediated by the Vent $\left(e x o^{-}\right)$polymerase are more difficult to rationalize based on this DFT analysis.

We have also modelled the possible H-bonded base pairs that are formed in the absence of $\mathrm{Ag}^{\mathrm{I}}$ (relative geometries are shown in Fig. 10b). All the base pairs have at least one strong N-H...N H-bond, along with one or more weak C-H...O/N H-bonds. Compared to classical dA:dT/dG:dC cWW geometries, the C1'-C1' distances between the H-bonded mispairs is larger for the $\mathbf{d P u r}^{\mathbf{P}}: \mathrm{dA}$ and $\mathbf{d P u r} \mathbf{r}^{\mathbf{P}}: \mathrm{dG}$ cWW base pairs, by $1.87 \AA$ and $1.95 \AA$ respectively, and shorter by $0.93 \AA$ for the $\mathbf{d P u r}^{\mathbf{P}}: \mathrm{dT} \mathrm{cWW}$ base pair. As for the $\mathbf{d P u r} \mathbf{r}^{\mathbf{P}}: \mathrm{dC}$ pair, its $C 1^{\prime}-\mathrm{C} 1$ ' distance is quite close $(10.22 \AA)$ to the canonical one. Therefore, especially the $\mathbf{d P u r} \mathbf{P}^{\mathbf{P}}: \mathrm{dA}$ and $\mathbf{d P u r}^{\mathrm{P}}$ : $\mathrm{dG}$ pairs seem geometrically unfit to be part of a regular DNA duplex in their $\mathrm{cWW}$ geometries. That notwithstanding, the $\mathbf{d P u r}^{\mathbf{P}}: \mathrm{dG} \mathrm{cWW}$ pair results to be in principle slightly more stable than the $\mathrm{dA}: \mathrm{dT}$ pair, both in the gas phase and in water (by -2.61 and $1.42 \mathrm{kcal} / \mathrm{mol}$ respectively). On the contrary, the dPur $^{\mathbf{P}}-\mathrm{dA} / \mathrm{dT} / \mathrm{dC}$ base pairs are less stable than the corresponding $\mathrm{dA}: \mathrm{dT}$ base pair with energy differences within 5.57 and $4.50 \mathrm{kcal} / \mathrm{mol}$, in the gas phase and in water, respectively (see Table S3).

As they appear unfit to match a regular duplex in their cWW geometries, we also modelled the $\mathbf{d P u r} \mathbf{P}^{\mathbf{P}}: \mathrm{dA}$ and $\mathbf{d P u r}^{\mathrm{P}}$ : $\mathrm{dG}$ base pairs in their cWH geometries. Interestingly, in the $\mathrm{cWH}$ geometry, the $\mathrm{C} 1$ '-C1' distance of the $\mathbf{d P u r}^{\mathbf{P}}$ : $\mathrm{dA}$ pair is extremely close $(10.33 \AA)$ to the "canonical" value, while its energy remains similar to that of the cWW geometry (with energy differences within $0.14 \mathrm{kcal} / \mathrm{mol}$ ). These findings clearly indicate that the preferred geometry for the $\mathbf{d P u r}^{\mathbf{P}}$ :dA pair, to be incorporated in a DNA duplex, would be the cWH one. In contrast, for $\mathbf{d P u r}^{\mathbf{P}}: \mathrm{dG}$ a cWH geometry could not be modelled, because of the unavailability of 
complementary H-bond donor/acceptor atoms on its facing edges (see Fig. 10). This analysis is in agreement with the experimental data showing that the $\mathbf{d P u r} \mathbf{P}^{\mathbf{P}}$ :dG pairing is not observed under enzymatic DNA synthesis.

a

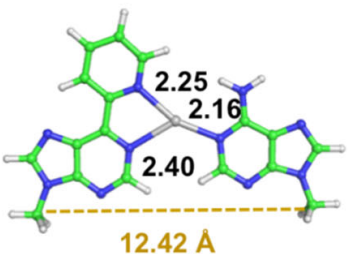

dPur $-\mathrm{Ag}^{+}-\mathrm{A}$ cWW-like

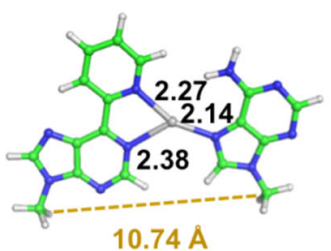

dPurP-Ag-A cWH-like

b

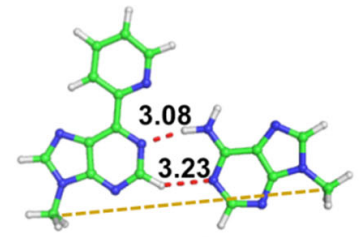

$12.46 \AA$

dPurP:A cWW

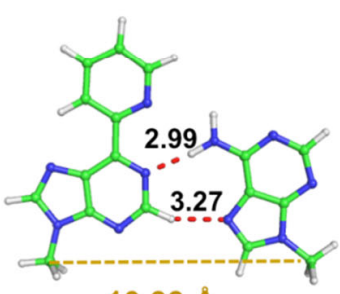

$10.33 \AA$

dPurP:A cWH

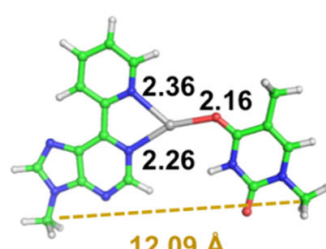

$12.09 \AA$
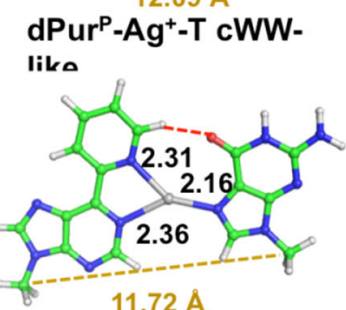

dPurP-Ag + -G cWH-like

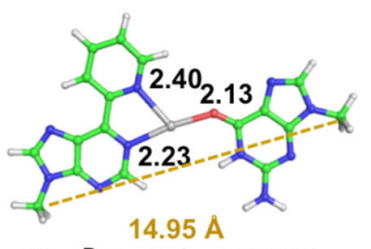

dPur $-\mathrm{Ag}^{+}-\mathrm{G}$ cWW-like

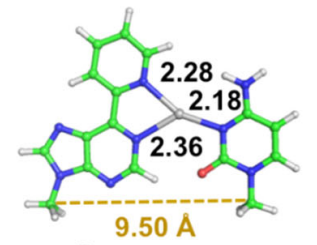

dPurP-Ag+-C cWW-like

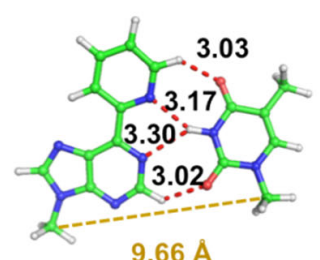

PurP:T cWW

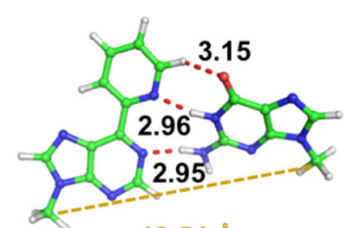

$12.54 \AA$

dPurP:G cWW

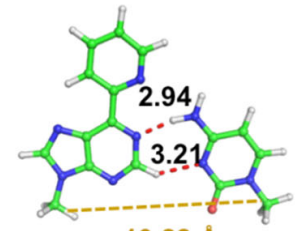

$10.22 \AA$

Figure 10. a) Geometry optimized structures of possible $\mathrm{Ag}^{\mathrm{I}}$ mediated base pairs between the non-natural dPur $^{\mathbf{P}}$ and natural nucleobases using Watson-Crick edge (W) and Hoogsteen edge $(\mathrm{H})$; b) Geometry optimized structures of mismatched H-bond mediated base pairs between $\mathbf{d P u r}^{\mathbf{P}}$ and natural nucleobases. Modelling of pairing of $\mathbf{d P u r}^{\mathbf{P}}$ and dG in a cWH geometry is not feasible due to the proximity of acceptor atoms opposite to each other, marked by red cross signs in figure. The natural nucleobases have been truncated at the $\mathrm{C} 1$ ' atom. 


\section{CONCLUSIONS}

The decoration of nucleic acids with metal ions through the formation of artificial metal base pairs is an alluring method for improving the chemical diversity and conferring additional properties to DNA and RNA. Nucleic acids containing metal base pairs have found applications in numerous fields including the construction of logic gate devices and the development of novel nanomaterials. ${ }^{65-68}$ The enzymatic construction of artificial metal base pairs represents an alluring alternative method that alleviates the synthetic burden and size limitation impaired to traditional approaches involving solid-phase synthesis. Here, we demonstrate that the two synthetic analogues $\mathbf{d I m}^{\mathbf{C}}$ and $\mathbf{d P u r} \mathbf{P}^{\mathbf{P}}$ can be used for the enzymatic synthesis of $\mathrm{Ag}^{\mathrm{I}}$-mediated UBPs. In addition, we have developed a two-step enzymatic method that permits the installation of a $\mathbf{d I m}^{\mathrm{C}}-\mathrm{Ag}^{\mathrm{I}}-\mathbf{d P} \mathbf{u r}^{\mathrm{P}}$ base pair followed by natural DNA synthesis and could be extended to any type of oligonucleotide. Interestingly, the metal preference under enzymatic DNA synthesis conditions appears to be the opposite of that unraveled by UV melting experiments on short synthetic oligonucleotides since $\mathrm{Ni}^{\mathrm{II}}$ strongly stabilized a $\mathbf{d P u r} \mathbf{r}^{\mathrm{P}}-\mathbf{d P u r}^{\mathrm{P}}$ mismatch while coordination to $\mathrm{Ag}^{\mathrm{I}}$ appeared to be possible but only mildly stabilizing. ${ }^{41}$ The DFT calculations support formation of $\mathrm{Ag}^{\mathrm{I}}$-mediated base pairs and shed some light into the mechanism of formation. Particularly, metal coordination of the templating nucleotide appears to be the first step in the formation of metal base pairs under enzymatic synthesis conditions. While PEX reactions performed with natural nucleotides reveal that the $\mathbf{d I m}^{\mathbf{C}}$ and dPur $^{P}$ system is not fully compatible with the construction of libraries for SELEX experiments due to misincorporation events, this study clearly demonstrates the possibility of synthesizing DNA duplexes containing artificial metal base pairs using PEX reactions. Collectively, the results demonstrate that the combination of a [2+2] metal coordination environment and increased stacking interactions offered by the $\mathbf{d I m}^{\mathrm{C}}-\mathrm{Ag}^{\mathrm{I}}-\mathbf{d P u} \mathbf{r}^{\mathrm{P}}$ base pair appear to be key elements for the design of nucleotide ligands for the enzymatic construction of metal UBPs.

\section{EXPERIMENTAL SECTION}

\section{Materials and Methods}

All reactions were performed under argon in flame-dried glassware. Anhydrous solvents for reactions were obtained from Sigma Aldrich. Flash chromatography was performed using silica gel (230-400 mesh) from Sigma Aldrich. Thin layer chromatography was carried out on pre-coated glass-backed plates of silica gel (0.25 mm, UV254) from Macherey-Nagel. All chemicals and solvents used were purchased from SigmaAldrich and Alfa Aesar. NMR spectra were recorded on a Bruker Avance 400 spectrometer $(400.13 \mathrm{MHz}$ for ${ }^{1} \mathrm{H}, 100.62 \mathrm{MHz}$ for ${ }^{13} \mathrm{C}$, and $161.62 \mathrm{MHz}$ for ${ }^{31} \mathrm{P}$ ) and all spectra were referenced to the signals of the corresponding solvent. Chemical shifts are given in ppm ( $\delta$ scale) and coupling constants $(J)$ in Hz. 
Assignation of the NMR signals was performed by using a combination of ${ }^{1} \mathrm{H} /{ }^{1} \mathrm{H}-\mathrm{COSY},{ }^{13} \mathrm{C}-\mathrm{DEPT}-135$, and ${ }^{13} \mathrm{C} /{ }^{1} \mathrm{H}-\mathrm{HMBC}$ experiments. Crude $\mathbf{d P u r}{ }^{\mathrm{P}} \mathbf{T P}$ was purified by HPLC using an $\mathrm{Ä}^{\mathrm{kta}}{ }^{\mathrm{TM}}$ pure system (GE Healthcare) equipped with Thermo Scientific ${ }^{\mathrm{TM}}$ DNAPac ${ }^{\mathrm{TM}}$ PA100 semi preparative ion exchange column

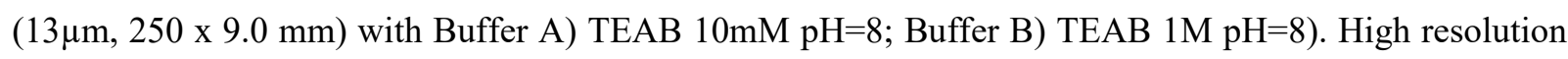
electrospray ionization (ESI) mass spectra (MS, $m / z$ ) were recorded on a Waters Q-Tof Micro MS in the positive-ion electrospray ionization $\left(\mathrm{ESI}^{+}\right)$mode. Solutions were prepared using 1:1 $\mathrm{MeCN} / \mathrm{H}_{2} \mathrm{O}$ containing $0.1 \%$ formic acid or $\mathrm{MeOH} /$ water containing $10 \mathrm{mM}$ ammonium acetate in the case of sensitive compounds. HPLC purification was performed using an Äkta ${ }^{\mathrm{TM}}$ pure system (GE Healthcare) equipped with Thermo Scientific ${ }^{\mathrm{TM}}$ DNAPac ${ }^{\mathrm{TM}}$ PA100 semi preparative ion exchange column $(13 \mu \mathrm{m}, 250$ x $9.0 \mathrm{~mm})$. Unmodified DNA oligonucleotides were purchased from Microsynth. DNA oligonucleotides containing modified nucleotides were synthesized on an H-8 DNA synthesizer from K\&A on a $1 \mu \mathrm{mol}$ scale. Natural DNA phosphoramidites (dT, dC4bz, dG2DMF, dA6Bz) and solid support (dA6Bz-lcaa-CPG 500A) were all purchased from ChemGenes. The phosphoramidite was prepared by application of literature protocols. ${ }^{45}$ Natural DNA phosphoramidites as well as the modified phosphoramidite were prepared as $0.07 \mathrm{M}$ solutions in $\mathrm{MeCN}$ and were coupled using $50 \mathrm{sec}$ and $490 \mathrm{sec}$ steps, respectively. 5-(ethylthio)-1H-tetrazole $(0.25$ $\mathrm{M}$ in $\mathrm{MeCN}$ ) was used as coupling agent. Capping, oxidation, and detritylation were performed using standard conditions. Cleavage from the solid support and deprotection of oligonucleotides was achieved by treatment with concentrated ammonia at $55^{\circ} \mathrm{C}$ for $16 \mathrm{~h}$. After centrifugation, the supernatants were collected and the resulting solutions were evaporated to dryness on a speed-vac. Crude oligonucleotides were purified by anion exchange HPLC (Dionex - DNAPac PA200). Buffer solutions of $25 \mathrm{mM}$ Tris- $\mathrm{HCl}$ in $\mathrm{H}_{2} \mathrm{O}$, pH 8.0 (buffer A) and $25 \mathrm{mM}$ Tris- $\mathrm{HCl}, 1.25 \mathrm{M} \mathrm{NaCl}$ in $\mathrm{H}_{2} \mathrm{O}, \mathrm{pH} 8.0$ (buffer B) were used. The purified oligonucleotides were then desalted with SepPack C-18 cartridges. Oligonucleotide concentrations were quantitated by UV spectroscopy using a UV5Nano spectrophotometer (Mettler Toledo). The chemical integrity of oligonucleotides was assessed by UPLC-MS analysis: UPLC was performed on a BEH C18 column (130 $\AA, 1.7 \mu \mathrm{m}, 2.1 \mathrm{~mm}$ x $50 \mathrm{~mm}$ ) from Waters, installed on an ACQUITY UPLC H-Class System (SQ Detector 2). A Buffer containing $20 \mathrm{mM}$ TEA and $400 \mathrm{mM} \mathrm{HFIP}$ in $\mathrm{H}_{2} \mathrm{O}$ was used with a linear gradient from 18 to $31 \%$ Methanol within 5 minutes and a flow rate of $0.3 \mathrm{~mL} / \mathrm{min}$. All the DNA polymerases (Therminator, Vent $(\text { exo })^{-}$, Deep Vent, Bst, Taq, and Klenow fragment of DNA polymerase I exo- (Kf (exo )) were purchased from New England Biolabs as well as the natural dNTPs. Acrylamide/bisacrylamide (29:1, 40\%) was obtained from Fisher Scientific. Visualization of PAGE gels was performed by fluorescence imaging using a using a Storm 860 or a Typhoon Trio phosphorimager with the ImageQuant software (both from GE Healthcare). The following salts were used: $\mathrm{AgNO}_{3}, \mathrm{CdCl}_{2}, \mathrm{CuSO}_{4}, \mathrm{CoCl}_{2}, \mathrm{EuCl}_{3}$, $\mathrm{FeSO}_{4}, \mathrm{FeCl}_{3}, \mathrm{HgCl}_{2}, \mathrm{MnCl}_{2}, \mathrm{NiSO}_{4}, \mathrm{~Pb}(\mathrm{OAc})_{2}, \mathrm{ZnSO}_{4}$.

\section{Reaction buffers}


The following 10x buffers without any $\mathrm{Cl}^{-}$source were prepared for PEX reactions in presence of $\mathrm{Ag}^{\mathrm{I}}$. Buffer 1 is used for Vent (exo-), buffer 2 for $\mathrm{Kf}\left(e^{-} o^{-}\right)$, buffer 3 for Taq and buffer 4 for Bst.

Buffer 1: $200 \mathrm{mM}$ Tris acetate, $100 \mathrm{mM}\left(\mathrm{NH}_{4}\right)_{2} \mathrm{SO}_{4}, 100 \mathrm{mM} \mathrm{KClO}_{4}, 20 \mathrm{mM} \mathrm{MgSO}_{4} 0.1 \%$ Triton ${ }^{\circledR} \mathrm{X}-100$, pH 8.8 at $25^{\circ} \mathrm{C}$; buffer 2: $500 \mathrm{mM} \mathrm{NaClO}_{4}, 100 \mathrm{mM}$ Tris acetate, $100 \mathrm{mM} \mathrm{MgSO}_{4}, 100 \mu \mathrm{M}$ DTT, pH 7.9; buffer 3: $100 \mathrm{mM}$ Tris acetate, $500 \mathrm{mM} \mathrm{KClO}_{4}, 15 \mathrm{mM} \mathrm{MgSO}_{4}, \mathrm{pH} 8.3$ at $25^{\circ} \mathrm{C}$; buffer 4: $200 \mathrm{mM}$ Tris acetate, $100 \mathrm{mM}\left(\mathrm{NH}_{4}\right)_{2} \mathrm{SO}_{4}, 500 \mathrm{mM} \mathrm{KClO}_{4}, 20 \mathrm{mM} \mathrm{MgSO}_{4}, 0.1 \%$ Tween® $20, \mathrm{pH} 8.8$ at $25^{\circ} \mathrm{C}$.

\section{Synthesis of dPur ${ }^{\mathrm{P}} \mathrm{TP}$}

Synthesis of 3'-O-acetyl-1-(2-deoxy-ß-D-ribofuranosyl)-adenine-6-pyridin-2-yl (6). Nucleoside analogue 4 [35] (200 mg, $0.367 \mathrm{mmol}, 1 \mathrm{eq}$ ) was dissolved in dry pyridine (2 mL) at RT under Ar. To this solution, 2-(dimethylamino)pyridine ( $9 \mathrm{mg}, 0.073 \mathrm{mmol}, 0.2 \mathrm{eq}$ ) was added followed by trimethylamine $(128 \mu \mathrm{L}, 0.919 \mathrm{mmol}, 2.5 \mathrm{eq})$ and subsequently acetic anhydride $(0.1 \mathrm{~mL}, 1.103 \mathrm{mmol}, 3 \mathrm{eq})$. After $1 \mathrm{~h}$ of stirring, the reaction mixture was quenched with $\mathrm{NaHCO}_{3}$ sat. $(20 \mathrm{~mL})$ and extracted with DCM $(3 \mathrm{x} 30$ $\mathrm{mL}$ ). The organic layers were combined, dried over $\mathrm{MgSO}_{4}$, and concentrated. The crude product was used in the second step without further purification. The starting material $5(120 \mathrm{mg}, 0.182 \mathrm{mmol}, 1 \mathrm{eq})$ was dissolved in anhydrous DCM $(5 \mathrm{~mL})$ under Ar. To this solution, $5 \mathrm{~mL}$ of TCA $3 \%$ in DCM $(5 \mathrm{~mL})$ was added. The reaction mixture was stirred for $30 \mathrm{~min}$ at room temperature. The solvent was removed in vacuo and the residue was purified by flash chromatography (DCM/MeOH 96:4) to give $45 \mathrm{mg}$ of a white solid (70\%). HR-MS for $\mathrm{C}_{17} \mathrm{H}_{18} \mathrm{~N}_{5} \mathrm{O}_{4}{ }^{+} \mathrm{m} / \mathrm{z}$ calcd: 356.1359; found: $356.1357 .{ }^{1} \mathrm{H}$ NMR (400 MHz, $\left.\mathrm{CDCl}_{3}\right) \delta=$ $2.16(\mathrm{~s}, 3 \mathrm{H}), 2.51-3.31(\mathrm{~m}, 2 \mathrm{H}), 3.95-4.05(\mathrm{~m}, 2 \mathrm{H}), 4.33(\mathrm{~s}, 1 \mathrm{H}), 5.61-5.63(\mathrm{~m}, 1 \mathrm{H}), 6.44-6.47(\mathrm{~m}, 1 \mathrm{H})$, 7.47-7.50 (m, 1H), 7.94-7.98 (m, 1H), $8.35(\mathrm{~s}, 1 \mathrm{H}), 8.83(\mathrm{~d}, J=8.0 \mathrm{~Hz}, 1 \mathrm{H}), 8.99$ (d, $J=4.0 \mathrm{~Hz}, 1 \mathrm{H}), 9.14$ (s, $1 \mathrm{H}) .{ }^{13} \mathrm{C} \mathrm{NMR}\left(101 \mathrm{MHz}, \mathrm{CDCl}_{3}\right) \delta=21.0,37.7,63.2,76.2,87.4,87.6,125.2,125.8,133.1,137.0$, 145.0, 150.4, 151.9, 153.3, 154.5, 170.3.

Synthesis of dPur ${ }^{\mathrm{P}}$ TP (3). Nucleoside 6 (45 $\left.\mathrm{mg}, 0.127 \mathrm{mmol}, 1 \mathrm{eq}\right)$ was dissolved in dry pyridine $(0.2 \mathrm{~mL})$ and dry dioxane $(0.4 \mathrm{~mL})$ at RT under Ar. To this clear solution, 2-chloro-1,3,2-benzodioxaphosphorin-4one $(38 \mathrm{mg}, 0.185,1.4$ eq.) was added and the reaction mixture was stirred for $45 \mathrm{~min}$. A solution of tributylammonium pyrophosphate $(120 \mathrm{mg}, 0.219 \mathrm{mmol}, 1.7 \mathrm{eq})$ in dry DMF $(0.1 \mathrm{~mL})$ and tributylamine $(60 \mu \mathrm{L})$ was added dropwise and the reaction mixture stirred for another $45 \mathrm{~min}$. The reaction mixture was then oxidized by the addition of iodine ( $64 \mathrm{mg}, 0.203 \mathrm{mmol}, 1.6 \mathrm{eq})$ in pyridine $(1 \mathrm{~mL})$ and $\mathrm{H}_{2} \mathrm{O}(0.2 \mathrm{~mL})$. After $30 \mathrm{~min}$ of stirring, the excess of iodine was quenched with a sodium thiosulfate solution $(10 \% \mathrm{w} / \mathrm{v}$ in water) and the resulting clear solution was concentrated under reduced pressure at $30^{\circ} \mathrm{C}$. The concentrated mixture was treated with ammonium hydroxide $30 \%(10 \mathrm{~mL})$ for $2 \mathrm{~h}$. The yellow suspension was again concentrated under reduced pressure at $30^{\circ} \mathrm{C}$. The yellow residue was dissolved in $\mathrm{H}_{2} \mathrm{O}(2 \mathrm{~mL})$ and 
precipitated by the addition of $\mathrm{NaClO}_{4} 2 \%$ in acetone $(12 \mathrm{~mL})$. The crude product was purified by ion exchange HPLC (50\% B in $20 \mathrm{~min}$; Buffer A) TEAB 10mM pH=8; Buffer B) TEAB $1 \mathrm{M} \mathrm{pH=8}$ ) to yield $5.6 \mathrm{mg}(8 \%)$ of pure triphosphate 3. HR-MS $\mathrm{C}_{15} \mathrm{H}_{17} \mathrm{P}_{3} \mathrm{~N}_{5} \mathrm{O}_{12}{ }^{-} \mathrm{m} / \mathrm{z}$ calcd: 552.0087 ; found: $552.0083 .{ }^{1} \mathrm{H}$ $\operatorname{NMR}\left(400 \mathrm{MHz}, \mathrm{D}_{2} \mathrm{O}\right) \delta=2.55-2.86(\mathrm{~m}, 2 \mathrm{H}), 2.94-3.26(\mathrm{~m}, 2 \mathrm{H}), 4.11-4.14(\mathrm{~m}, 2 \mathrm{H}), 4.24(\mathrm{~s}, 1 \mathrm{H}), 6.62(\mathrm{t}$, 1H), 7.57 (s, 1H), $8.04(\mathrm{~s}, 1 \mathrm{H}), 8.30$ (s, 1H), 8.69 (s, 1H), 8.81 (s, 1H), 8.96 (s, 1H). ${ }^{31} \mathrm{P}$ NMR $(202 \mathrm{MHz}$, $\left.\mathrm{D}_{2} \mathrm{O}\right) \delta=-26.18(\mathrm{t}, J=22.2 \mathrm{~Hz} 1 \mathrm{P}),-14.40(\mathrm{~d}, J=20.2 \mathrm{~Hz} 1 \mathrm{P}),-13.74(\mathrm{~d}, J=18.2 \mathrm{~Hz} 1 \mathrm{P})$.

\section{Primer extension experiments}

The 5'-FAM-labelled primer P1 (10 pmol) was annealed to the appropriate template (15 pmol) in water by heating to $95^{\circ} \mathrm{C}$ and then gradually cooling down to room temperature (over $30 \mathrm{~min}$ ). The appropriate DNA polymerase and metal cation solutions were then added to the annealed oligonucleotides mixture on ice. Finally, natural dNTPs and/or modified triphosphate were added for a total reaction volume of $10 \mu \mathrm{L}$. Following incubation at the optimal temperature for the enzyme, the reactions were quenched by adding stop solution (10 $\mu \mathrm{L}$; formamide $(70 \%)$, ethylenediaminetetraacetic acid (EDTA; $50 \mathrm{mM}$ ), bromophenol $(0.1 \%)$, xylene cyanol $(0.1 \%))$. The reaction mixtures were subjected to gel electrophoresis in denaturing polyacrylamide gel $(20 \%)$ containing trisborate-EDTA (TBE) $1 \times$ buffer $(\mathrm{pH} 8)$ and urea $(7 \mathrm{M})$. Visualization was performed by fluorescence imaging a using a Storm 860 or a Typhoon Trio phosphorimager. Polygons were drawn around the bands corresponding to the unmodified primer and the reaction products and volumes were quantified using the ImageQuant software (GE Healthcare). Yields of product formation were then determined by application of the following equation:

$$
\text { yield }=\frac{v_{n+1}}{\left(v_{n}+v_{n+1}\right)} \times 100 \quad \text { Eq. (1) }
$$

Where $\mathrm{v}_{\mathrm{n}}$ and $\mathrm{v}_{\mathrm{n}+1}$ correspond to the volumes of unmodified primer and of the $\mathrm{n}+1$ product, respectively.

\section{Computational details}

Geometry optimizations were performed within a DFT approach, based on the hybrid B3LYP functional ${ }^{69-}$ ${ }^{70}$ as implemented in the Gaussian09 package. The correlation-consistent polarized valence double-z-cc$\mathrm{pVDZ}^{71}$ basis set was used for all the geometry optimizations in gas phase. Since dispersion interactions might contribute differently to the stability of the base pairs under study, we also added an empirical dispersion term, with the Becke-Johnson damping scheme, to the electronic energy using empirical dispersion $=$ GD3BJ keyword. ${ }^{72-73}$ Interaction energies were calculated on the B3LYP-D3BJ/cc-pVDZ optimized geometries at the M06 level ${ }^{74}$ of theory using the cc-pVTZ basis set. For the anionic oxygen atom as in $\mathrm{Im}^{\mathrm{C}}$, an augmented aug-cc-pVTZ basis set is used. The energies have been calculated both in gas phase 
and in water, modeled with the C-PCM continuum solvation model ${ }^{75}$ For calculation of the geometries and energies for Ag, we used the small-core, quasi-relativistic Stuttgart/Dresden effective core potential with an associated valence contracted basis set (standard SDD keywords in Gaussian 09). ${ }^{76-78}$ Besides the optimizations with no symmetry constraints ( $\mathrm{C}_{1}$ symmetry), we have also imposed Cs symmetry on the simulated non-natural base pairs in order to mimic the planarity of base pairs under study, situation in the DNA double helical structure.

Thus, the binding energy $E_{\text {Bind }}$ is calculated as in Eq. 2:

$$
E_{\mathrm{Bind}}=E_{\mathrm{Complex}}-\left(E_{\mathrm{M} 1}+E_{\mathrm{M} 2}+E_{\mathrm{Metal}}\right)
$$

where $E_{\text {Complex }}$ is the electronic energies of the optimized complex (that is, M1-M2-metal base pair), and $E_{\mathrm{M} 1}$ and $E_{\mathrm{M} 2}$ and $E_{\mathrm{Metal}}$ are the electronic energy of the isolated optimized M1 and $\mathrm{M} 2$ bases, and respective complexed metal ion $\left(\mathrm{Ag}^{+}\right)$. In addition, binding energies of $\mathrm{H}$-bonded base pairs are also calculated. This is a rather standard approach used in this kind of calculations. ${ }^{79-84}$

\section{SUPPORTING INFORMATION}

The supplementary information contains the full characterization data of all compounds and modified oligonucleotides, additional gel images of primer extension reactions, additional geometry optimizations, and the XYZ coordinates for metal base pairs.

\section{ACKNOWLEDGEMENTS}

M.F. gratefully acknowledges a fellowship from the doctoral school MTCI University of Paris Descartes. The authors gratefully acknowledge financial support from Institut Pasteur. The start-up company DNA Script is acknowledged for help in the UPLC-MS analysis of the oligonucleotides. L.C. and M. C. acknowledges King Abdullah University of Science and Technology (KAUST) for support and the KAUST Supercomputing Laboratory for providing computational resources of the supercomputer Shaheen II. R.O. thanks MIUR-FFABR (Fondo per il Finanziamento Attività Base di Ricerca) for funding. This work was financially supported by an ERC Consolidator Grant PhotoMedMet to G.G. (GA 681679) and has received

support under the program "Investissements d' Avenir" launched by the French Government and implemented by the ANR with the reference ANR-10-IDEX-0001-02 PSL (G.G.).

\section{CONFLICTS OF INTEREST}

The authors declare no competing interests. 


\section{REFERENCES}

1. Lee, K. H.; Hamashima, K.; Kimoto, M.; Hirao, I., Genetic alphabet expansion biotechnology by creating unnatural base pairs. Curr. Opin. Biotechol. 2018, 51, 8-15.

2. Malyshev, D. A.; Romesberg, F. E., The Expanded Genetic Alphabet. Angew. Chem. Int. Ed. 2015, 54 (41), 11930-11944.

3. Georgiadis, M. M.; Singh, I.; Kellett, W. F.; Hoshika, S.; Benner, S. A.; Richards, N. G. J., Structural Basis for a Six Nucleotide Genetic Alphabet. J. Am. Chem. Soc. 2015, 137 (21), 6947-6955.

4. Hoshika, S.; Leal, N. A.; Kim, M. J.; Kim, M. S.; Karalkar, N. B.; Kim, H. J.; Bates, A. M.; Watkins, N. E.; SantaLucia, H. A.; Meyer, A. J.; DasGupta, S.; Piccirilli, J. A.; Ellington, A. D.; SantaLucia, J.; Georgiadis, M. M.; Benner, S. A., Hachimoji DNA and RNA: A genetic system with eight building blocks. Science 2019, 363 (6429), 884-887.

5. Ledbetter, M. P.; Karadeema, R. J.; Romesberg, F. E., Reprograming the Replisome of a Semisynthetic Organism for the Expansion of the Genetic Alphabet. J. Am. Chem. Soc. 2018, 140 (2), 758765.

6. Betz, K.; Kimoto, M.; Diederichs, K.; Hirao, I.; Marx, A., Structural Basis for Expansion of the Genetic Alphabet with an Artificial Nucleobase Pair. Angew. Chem. Int. Ed. 2017, 56 (39), 12000-12003.

7. Hamashima, K.; Soong, Y. T.; Matsunaga, K.; Kimoto, M.; Hirao, I., DNA Sequencing Method Including Unnatural Bases for DNA Aptamer Generation by Genetic Alphabet Expansion. ACS Synth. Biol. 2019, 8 (6), 1401-1410.

8. Feldmann, A. W.; Romesberg, F. E., Expansion of the Genetic Alphabet: A Chemist's Approach to Synthetic Biology. Acc. Chem. Res. 2018, 51 (2), 394-403.

9. Malyshev, D. A.; Dhami, K.; Lavergne, T.; Chen, T. J.; Dai, N.; Foster, J. M.; Correa, I. R.; Romesberg, F. E., A semi-synthetic organism with an expanded genetic alphabet. Nature 2014, 509 (7500), 385-388.

10. Zhang, Y. K.; Lamb, B. M.; Feldman, A. W.; Zhou, A. X.; Lavergne, T.; Li, L. J.; Romesberg, F. E., A semisynthetic organism engineered for the stable expansion of the genetic alphabet. Proc. Natl. Acad. Sci. U.S.A. 2017, 114 (6), 1317-1322.

11. Matsunaga, K.; Kimoto, M.; Hirao, I., High-Affinity DNA Aptamer Generation Targeting von Willebrand Factor A1-Domain by Genetic Alphabet Expansion for Systematic Evolution of Ligands by Exponential Enrichment Using Two Types of Libraries Composed of Five Different Bases. J. Am. Chem. Soc. 2017, 139 (1), 324-334.

12. Kimoto, M.; Yamashige, R.; Matsunaga, K.; Yokoyama, S.; Hirao, I., Generation of high-affinity DNA aptamers using an expanded genetic alphabet. Nat. Biotech. 2013, 31 (5), 453-457.

13. Dunn, M. R.; Jimenez, R. M.; Chaput, J. C., Analysis of aptamer discovery and technology. Nat. Rev. Chem. 2017, 1 (10), 16.

14. Zhang, L. Q.; Yang, Z. Y.; Sefah, K.; Bradley, K. M.; Hoshika, S.; Kim, M. J.; Kim, H. J.; Zhu, G. Z.; Jimenez, E.; Cansiz, S.; Teng, I. T.; Champanhac, C.; McLendon, C.; Liu, C.; Zhang, W.; Gerloff, D. L.; Huang, Z.; Tan, W. H.; Benner, S. A., Evolution of Functional Six-Nucleotide DNA. J. Am. Chem. Soc. 2015, 137 (21), 6734-6737.

15. Cheung, Y.-W.; Röthlisberger, P.; Mechaly, A. E.; Weber, P.; Levi-Acobas, F.; Lo, Y.; Wong, A. W. C.; Kinghorn, A. B.; Haouz, A.; Savage, G. P.; Hollenstein, M.; Tanner, J. A., Evolution of abiotic cubane chemistries in a nucleic acid aptamer allows selective recognition of a malaria biomarker. Proc. Natl. Acad. Sci. U.S.A. 2020, 117 (29), 16790-16798. doi:10.1073/pnas.2003267117.

16. Jash, B.; Müller, J., Metal-Mediated Base Pairs: From Characterization to Application. Chem.-Eur. J. 2017, 23 (68), 17166-17178.

17. Takezawa, Y.; Müller, J.; Shionoya, M., Artificial DNA Base Pairing Mediated by Diverse Metal Ions. Chem. Lett. 2017, 46 (5), 622-633.

18. Kim, E. K.; Switzer, C., Polymerase Recognition of a Watson-Crick-Like Metal-Mediated Base Pair: Purine-2,6-Dicarboxylate Copper(II) Pyridine. ChemBioChem 2013, 14 (18), 2403-2407. 
19. Kaul, C.; Müller, M.; Wagner, M.; Schneider, S.; Carell, T., Reversible bond formation enables the replication and amplification of a crosslinking salen complex as an orthogonal base pair. Nat. Chem. 2011, 3 (10), 794-800.

20. Müller, S. L.; Zhou, X. L.; Leonard, P.; Korzhenko, O.; Daniliuc, C.; Seela, F., Functionalized Silver-Ion-Mediated -dC/-dC Hybrid Base Pairs with Exceptional Stability: -d-5-Iodo-2-Deoxycytidine and Its Octadiynyl Derivative in Metal DNA. Chem.-Eur. J. 2019, 25 (12), 3077-3090.

21. Müller, J., Nucleic acid duplexes with metal-mediated base pairs and their structures. Coord. Chem. Rev. 2019, 393, 37-47.

22. Schmidt, O. P.; Jurt, S.; Johannsen, S.; Karimi, A.; Sigel, R. K. O.; Luedtke, N. W., Concerted dynamics of metallo-base pairs in an A/B-form helical transition. Nat. Commun. 2019, 10, 11.

23. Ono, A.; Kanazawa, H.; Ito, H.; Goto, M.; Nakamura, K.; Saneyoshi, H.; Kondo, J., Novel DNA Helical Wire Containing Hg-II-Mediated T:T and T:G Pairs. Angew. Chem. Int. Ed. 2019, 58 (47), 1683516838.

24. Aro-Heinila, A.; Lönnberg, T.; Virta, P., 3-Fluoro-2-mercuri-6-methylaniline Nucleotide as a HighAffinity Nucleobase-Specific Hybridization Probe. Bioconjugate Chem. 2019, .30 (8), 2183-2190.

25. Ukale, D. U.; Lönnberg, T., 2,6-Dimercuriphenol as a Bifacial Dinuclear Organometallic Nucleobase. Angew. Chem. Int. Ed. 2018, 57 (49), 16171-16175.

26. Sandmann, N.; Defayay, D.; Hepp, A.; Müller, J., Metal-mediated base pairing in DNA involving the artificial nucleobase imidazole-4-carboxylate. J. Inorg. Biochem. 2019, 191, 85-93.

27. Takezawa, Y.; Nakama, T.; Shionoya, M., Enzymatic Synthesis of $\mathrm{Cu}(\mathrm{II})$-Responsive Deoxyribozymes through Polymerase Incorporation of Artificial Ligand-Type Nucleotides. J. Am. Chem. Soc. 2019, 141 (49), 19342-19350.

28. Fujii, A.; Nakagawa, O.; Kishimoto, Y.; Okuda, T.; Nakatsuji, Y.; Nozaki, N.; Kasahara, Y.; Obika, S., 1,3,9-Triaza-2-oxophenoxazine: An Artificial Nucleobase Forming Highly Stable Self-Base Pairs with Three Ag-I Ions in a Duplex. Chem.-Eur. J. 2019, 25 (31), 7443-7448.

29. Guo, X. R.; Leonard, P.; Ingale, S. A.; Seela, F., Gemcitabine, Pyrrologemcitabine, and 2 '-Fluoro2 '-Deoxycytidines: Synthesis, Physical Properties, and Impact of Sugar Fluorination on Silver Ion Mediated Base Pairing. Chem.-Eur. J. 2017, 23 (70), 17740-17754.

30. Jash, B.; Scharf, P.; Sandmann, N.; Guerra, C. F.; Megger, D. A.; Müller, J., A metal-mediated base pair that discriminates between the canonical pyrimidine nucleobases. Chem. Sci. 2017, 8 (2), 1337-1343.

31. Wang, Q.; Xie, X. Y.; Han, J.; Cui, G. L., QM and QM/MM Studies on Excited-State Relaxation Mechanisms of Unnatural Bases in Vacuo and Base Pairs in DNA. J. Phys. Chem. B. 2017, 121 (46), 1046710478.

32. Pollum, M.; Ashwood, B.; Jockusch, S.; Lam, M.; Crespo-Hernandez, C. E., Unintended Consequences of Expanding the Genetic Alphabet. J. Am. Chem. Soc. 2016, 138 (36), 11457-11460.

33. Freeman, R.; Finder, T.; Willner, I., Multiplexed Analysis of $\mathrm{Hg} 2+$ and Ag+ Ions by Nucleic Acid Functionalized CdSe/ZnS Quantum Dots and Their Use for Logic Gate Operations. Angew. Chem. Int. Ed. 2009, 48 (42), 7818-7821.

34. Kondo, J.; Tada, Y.; Dairaku, T.; Hattori, Y.; Saneyoshi, H.; Ono, A.; Tanaka, Y., A metallo-DNA nanowire with uninterrupted one-dimensional silver array. Nat. Chem. 2017, 9 (10), 956-960.

35. Naskar, S.; Guha, R.; Müller, J., Metal-Modified Nucleic Acids: Metal-Mediated Base Pairs, Triples, and Tetrads. Angew. Chem. Int. Ed. 2020, 59 (4), 1397-1406.

36. Kobayashi, T.; Takezawa, Y.; Sakamoto, A.; Shionoya, M., Enzymatic synthesis of ligand-bearing DNAs for metal-mediated base pairing utilising a template-independent polymerase. Chem. Commun. 2016, 52 (19), 3762-3765.

37. Levi-Acobas, F.; Röthlisberger, P.; Sarac, I.; Marliere, P.; Herdewijn, P.; Hollenstein, M., On the Enzymatic Formation of Metal Base Pairs with Thiolated and pKa-Perturbed Nucleotides. ChemBioChem 2019, 20 (24), 3032-3040.

38. Takezawa, Y.; Kobayashi, T.; Shionoya, M., The Effects of Magnesium Ions on the Enzymatic Synthesis of Ligand-Bearing Artificial DNA by Template-Independent Polymerase. Int. J. Mol. Sci. 2016, 17 (6), 10. 
39. Röthlisberger, P.; Levi-Acobas, F.; Sarac, I.; Marliere, P.; Herdewijn, P.; Hollenstein, M., On the enzymatic incorporation of an imidazole nucleotide into DNA. Org. Biomol. Chem. 2017, 15 (20), 44494455.

40. Röthlisberger, P.; Levi-Acobas, F.; Sarac, I.; Marliere, P.; Herdewijn, P.; Hollenstein, M., Towards the enzymatic formation of artificial metal base pairs with a carboxy-imidazole-modified nucleotide. $J$. Inorg. Biochem. 2019, 191, 154-163.

41. Switzer, C.; Sinha, S.; Kim, P. H.; Heuberger, B. D., A purine-like nickel(II) base pair for DNA. Angew. Chem. Int. Ed. 2005, 44 (10), 1529-1532.

42. Morales, J. C.; Kool, E. T., Minor groove interactions between polymerase and DNA: More essential to replication than Watson-Crick hydrogen bonds? J. Am. Chem. Soc. 1999, 121 (10), 2323-2324. 43. Ludwig, J.; Eckstein, F., Rapid and efficient synthesis of nucleoside 5'-O-(1-thiotriphosphates), 5'triphosphates and 2',3'-cyclophosphorothioates using 2-chloro-4H-1,3,2-benzodioxaphosphorin-4-one. $J$. Org. Chem. 1989, 54 (3), 631-635.

44. Hocek, M., Enzymatic Synthesis of Base-Functionalized Nucleic Acids for Sensing, Cross-linking, and Modulation of Protein-DNA Binding and Transcription. Accounts Chem. Res. 2019, 52 (6), 1730-1737. 45. Pochet, S.; Dugue, L., Imidazole-4-carboxamide and 1,2,4-triazole-3-carboxamide deoxynucleotides as simplified DNA building blocks with ambiguous pairing capacity. Nucleosides Nucleotides 1998, 17 (9-11), 2003-2009.

46. Vashishtha, A. K.; Wang, J. M.; Konigsberg, W. H., Different Divalent Cations Alter the Kinetics and Fidelity of DNA Polymerases. J. Biol. Chem. 2016, 291 (40), 20869-20875.

47. Flamme, M.; Levi-Acobas, F.; Hensel, S.; Naskar, S.; Röthlisberger, P.; Sarac, I.; Gasser, G.; Müller, J.; Hollenstein, M., Effect of metal shielding on the enzymatic construction of artificial base pairs. ChemBioChem 2020, ASAP, 10.1002/cbic.202000402.

48. Larsen, A. C.; Dunn, M. R.; Hatch, A.; Sau, S. P.; Youngbull, C.; Chaput, J. C., A general strategy for expanding polymerase function by droplet microfluidics. Nat. Commun. 2016, 7, 9.

49. Tabor, S.; Richardson, C. C., Effect of manganese ions on the incorporation of dideoxynucleotides by bacteriophage T7 DNA polymerase and Escherichia Coli DNA polymerase I. Proc. Natl. Acad. Sci. U.S.A. 1989, 86 (11), 4076-4080.

50. Sinha, I.; Fonseca Guerra, C.; Müller, J., A Highly Stabilizing Silver(I)-Mediated Base Pair in Parallel-Stranded DNA. Angew. Chem. Int. Ed. 2015, 54 (12), 3603-3606.

51. Kalra, K.; Gorle, S.; Cavallo, L.; Oliva, R.; Chawla, M., Occurrence and stability of lone pair- $\pi$ and $\mathrm{OH}-\pi$ interactions between water and nucleobases in functional RNAs. Nucleic Acids Res. 2020, 48 (11), 5825-5838.

52. Leontis, N. B.; Stombaugh, J.; Westhof, E., The non-Watson-Crick base pairs and their associated isostericity matrices. Nucleic Acids Res. 2002, 30 (16), 3497-3531.

53. Jana, S. K.; Guo, X. R.; Mei, H.; Seela, F., Robust silver-mediated imidazolo-dC base pairs in metal DNA: dinuclear silver bridges with exceptional stability in double helices with parallel and antiparallel strand orientation. Chem. Commun. 2015, 51 (97), 17301-17304.

54. Leontis, N. B.; Stombaugh, J.; Westhof, E., The non-Watson-Crick base pairs and their associated isostericity matrices. Nucleic Acids Res. 2002, 30 (16), 3497-3531.

55. Poater, J.; Swart, M.; Bickelhaupt, F. M.; Fonseca Guerra, C., B-DNA structure and stability: the role of hydrogen bonding, pi-pi stacking interactions, twist-angle, and solvation. Org Biomol Chem 2014, 12 (26), 4691-4700.

56. Delaney, J. C.; Gao, J. M.; Liu, H. B.; Shrivastav, N.; Essigmann, J. M.; Kool, E. T., Efficient Replication Bypass of Size-Expanded DNA Base Pairs in Bacterial Cells. Angew. Chem. Int. Ed. 2009, 48 (25), 4524-4527.

57. Matsuda, S.; Henry, A. A.; Schultz, P. G.; Romesberg, F. E., The effect of minor-groove hydrogenbond acceptors and donors on the stability and replication of four unnatural base pairs. J. Am. Chem. Soc. 2003, $125(20), 6134-6139$. 
58. Nakama, T.; Takezawa, Y.; Sasaki, D.; Shionoya, M., Allosteric Regulation of DNAzyme Activities through Intrastrand Transformation Induced by $\mathrm{Cu}(\mathrm{II})-$ Mediated Artificial Base Pairing. J. Am. Chem. Soc. 2020, 142 (22), 10153-10162.

59. Bauwens, B.; Rozenski, J.; Herdewijn, P.; Robben, J., A Single Amino Acid Substitution in Therminator DNA Polymerase Increases Incorporation Efficiency of Deoxyxylonucleotides. ChemBioChem 2018, 19 (22), 2410-2420.

60. Gardner, A. F.; Jackson, K. M.; Boyle, M. M.; Buss, J. A.; Potapov, V.; Gehring, A. M.; Zatopek, K. M.; Correa, I. R.; Ong, J. L.; Jack, W. E., Therminator DNA Polymerase: Modified Nucleotides and Unnatural Substrates. Front. Mol. Biosci. 2019, 6, 9.

61. Diafa, S.; Evequoz, D.; Leumann, C. J.; Hollenstein, M., Enzymatic Synthesis of 7,5-Bicyclo-DNA Oligonucleotides. Chem.-Asian J. 2017, 12 (12), 1347-1352.

62. Hwang, G. T.; Romesberg, F. E., Unnatural Substrate Repertoire of A, B, and X Family DNA Polymerases. J. Am. Chem. Soc. 2008, 130 (44), 14872-14882.

63. Jang, M.-Y.; Song, X.-P.; Froeyen, M.; Marlière, P.; Lescrinier, E.; Rozenski, J.; Herdewijn, P., A Synthetic Substrate of DNA Polymerase Deviating from the Bases, Sugar, and Leaving Group of Canonical Deoxynucleoside Triphosphates. Chem. Biol. 2013, 20 (3), 416-423.

64. Funai, T.; Miyazaki, Y.; Aotani, M.; Yamaguchi, E.; Nakagawa, O.; Wada, S.; Torigoe, H.; Ono, A.; Urata, H., AgI Ion Mediated Formation of a C-A Mispair by DNA Polymerases. Angew. Chem. Int. Ed. 2012, 51 (26), 6464-6466.

65. Xiao, M. S.; Lai, W.; Man, T. T.; Chang, B. B.; Li, L.; Chandrasekaran, A. R.; Pei, H., Rationally Engineered Nucleic Acid Architectures for Biosensing Applications. Chem. Rev. 2019, 119 (22), 1163111717.

66. Vecchioni, S.; Capece, M. C.; Toomey, E.; Nguyen, L.; Ray, A.; Greenberg, A.; Fujishima, K.; Urbina, J.; Paulino-Lima, I. G.; Pinheiro, V.; Shih, J.; Wessel, G.; Wind, S. J.; Rothschild, L., Construction and characterization of metal ion-containing DNA nanowires for synthetic biology and nanotechnology. Sci. Rep. 2019, 9, 15.

67. Yang, H.; McLaughlin, C. K.; Aldaye, F. A.; Hamblin, G. D.; Rys, A. Z.; Rouiller, I.; Sleiman, H. F., Metal-nucleic acid cages. Nat. Chem. 2009, 1 (5), 390-396.

68. Jash, B.; Müller, J., Stable Copper(I)-Mediated Base Pairing in DNA. Angew. Chem. Int. Ed. 2018, 57 (30), 9524-9527.

69. Becke, A. D., Density-Functional Exchange-Energy Approximation with Correct AsymptoticBehavior. Phys. Rev. A 1988, 38 (6), 3098-3100.

70. Becke, A. D., Density-Functional Thermochemistry .3. The Role of Exact Exchange. J. Chem. Phys. 1993, 98 (7), 5648-5652.

71. Dunning, T. H., Gaussian-Basis Sets for Use in Correlated Molecular Calculations .1. The Atoms Boron through Neon and Hydrogen. J. Chem. Phys. 1989, 90 (2), 1007-1023.

72. Grimme, S.; Antony, J.; Ehrlich, S.; Krieg, H., A consistent and accurate ab initio parametrization of density functional dispersion correction (DFT-D) for the 94 elements H-Pu. J. Chem. Phys. 2010, 132 (15), 154104.

73. Grimme, S.; Ehrlich, S.; Goerigk, L., Effect of the Damping Function in Dispersion Corrected Density Functional Theory. J. Comput. Chem. 2011, 32 (7), 1456-1465.

74. Zhao, Y.; Truhlar, D. G., The M06 suite of density functionals for main group thermochemistry, thermochemical kinetics, noncovalent interactions, excited states, and transition elements: two new functionals and systematic testing of four M06-class functionals and 12 other functionals. Theor. Chem. Acc. 2008, 120 (1-3), 215-241.

75. Klamt, A.; Schuurmann, G., Cosmo - a New Approach to Dielectric Screening in Solvents with Explicit Expressions for the Screening Energy and Its Gradient. J. Chem. Soc.-Perkin Trans. 2 1993, (5), 799-805.

76. Leininger, T.; Nicklass, A.; Stoll, H.; Dolg, M.; Schwerdtfeger, P., The accuracy of the pseudopotential approximation .2. A comparison of various core sizes for indium pseudopotentials in calculations for spectroscopic constants of InH, InF, and InCl. J. Chem. Phys. 1996, 105 (3), 1052-1059. 
77. Kuchle, W.; Dolg, M.; Stoll, H.; Preuss, H., Energy-Adjusted Pseudopotentials for the Actinides Parameter Sets and Test Calculations for Thorium and Thorium Monoxide. J. Chem. Phys. 1994, 100 (10), $7535-7542$.

78. Haussermann, U.; Dolg, M.; Stoll, H.; Preuss, H.; Schwerdtfeger, P.; Pitzer, R. M., Accuracy of Energy-Adjusted Quasi-Relativistic Abinitio Pseudopotentials - All-Electron and Pseudopotential Benchmark Calculations for Hg, Hgh and Their Cations. Mol. Phys. 1993, 78 (5), 1211-1224.

79. Chawla, M.; Autiero, I.; Oliva, R.; Cavallo, L., Energetics and dynamics of the non-natural fluorescent 4AP:DAP base pair. Phys Chem Chem Phys 2018, 20 (5), 3699-3709.

80. Chawla, M.; Credendino, R.; Oliva, R.; Cavallo, L., Structural and Energetic Impact of Non-Natural 7-Deaza-8-Azaadenine and Its 7-Substituted Derivatives on H-Bonding Potential with Uracil in RNA Molecules. J. Phys. Chem. B 2015, 119 (41), 12982-12989.

81. Chawla, M.; Minenkov, Y.; Vu, K. B.; Oliva, R.; Cavallo, L., Structural and Energetic Impact of Non-natural 7-Deaza-8-azaguanine, 7-Deaza-8-azaisoguanine, and Their 7-Substituted Derivatives on Hydrogen-Bond Pairing with Cytosine and Isocytosine. ChemBioChem 2019, 20 (17), 2262-2270.

82. Chawla, M.; Oliva, R.; Bujnicki, J. M.; Cavallo, L., An atlas of RNA base pairs involving modified nucleobases with optimal geometries and accurate energies. Nucleic Acids Res. 2015, 43 (14), 6714-6729.

83. Chawla, M.; Poater, A.; Besalu-Sala, P.; Kalra, K.; Oliva, R.; Cavallo, L., Theoretical characterization of sulfur-to-selenium substitution in an emissive RNA alphabet: impact on H-bonding potential and photophysical properties. Phys Chem Chem Phys 2018, 20 (11), 7676-7685.

84. Sinha, I.; Fonseca Guerra, C.; Müller, J., A highly stabilizing silver(I)-mediated base pair in parallelstranded DNA. Angew Chem Int Ed Engl 2015, 54 (12), 3603-3606.

\section{For Table of Contents Only}

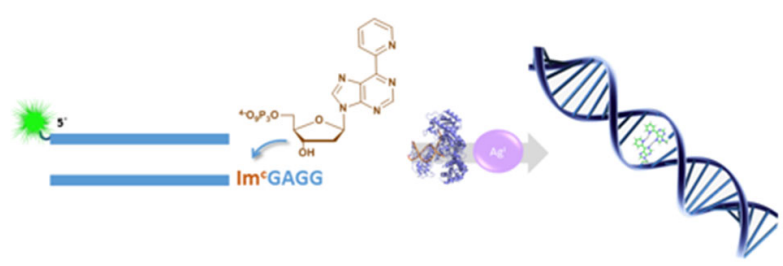

